\title{
Compact Process Development at Babcock \& Wilcox
}

Jeffrey Phillips and Eric Shaber

The INL is a

U.S. Department of Energy

National Laboratory

operated by

Battelle Energy Alliance

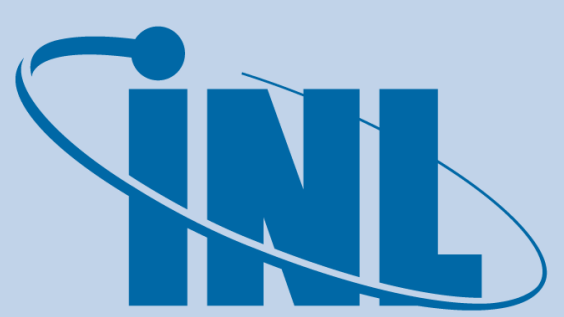

Idaho National Laboratory

\section{March 2012}

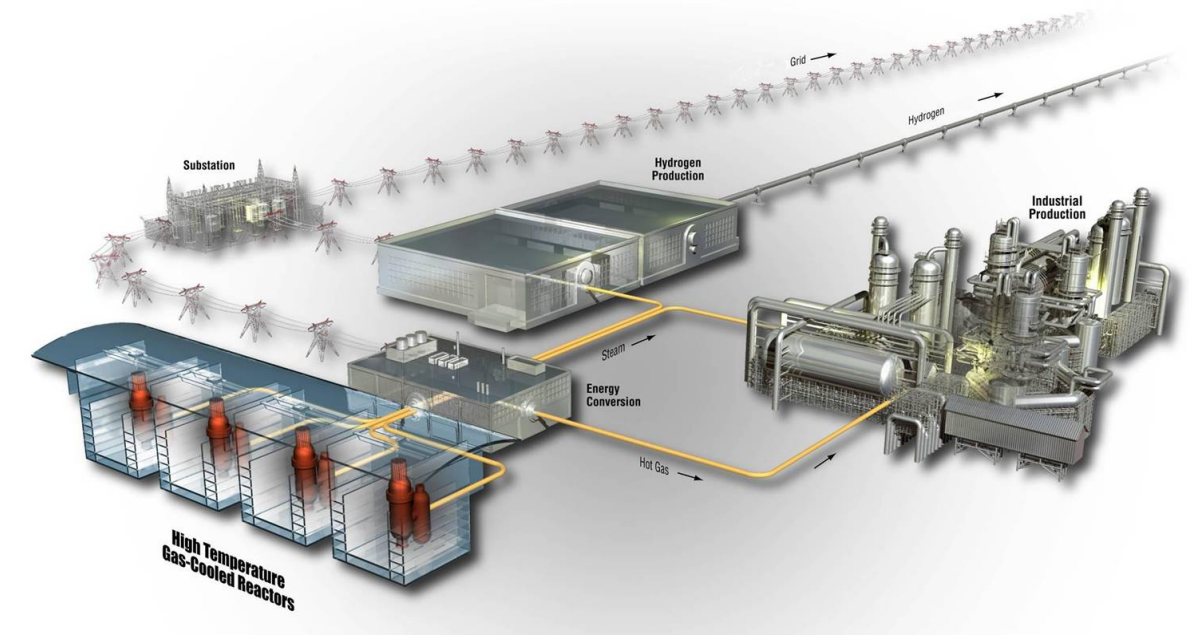




\section{DISCLAIMER}

This information was prepared as an account of work sponsored by an agency of the U.S. Government. Neither the U.S. Government nor any agency thereof, nor any of their employees, makes any warranty, expressed or implied, or assumes any legal liability or responsibility for the accuracy, completeness, or usefulness, of any information, apparatus, product, or process disclosed, or represents that its use would not infringe privately owned rights. References herein to any specific commercial product, process, or service by trade name, trade mark, manufacturer, or otherwise, does not necessarily constitute or imply its endorsement, recommendation, or favoring by the U.S. Government or any agency thereof. The views and opinions of authors expressed herein do not necessarily state or reflect those of the U.S. Government or any agency thereof. 
INL/EXT-11-23166

Revision 0

\title{
Compact Process Development at Babcock \& Wilcox
}

\author{
Jeffrey Phillips and Eric Shaber
}

March 2012

\begin{abstract}
Idaho National Laboratory Very High Temperature Reactor Program Idaho Falls, Idaho 83415
\end{abstract}

http://www.inl.gov

Prepared for the

U.S. Department of Energy

Office of Nuclear Energy

Under DOE Idaho Operations Office

Contract DE-AC07-05ID14517 



\section{Very High Temperature Reactor Program}

\section{Compact Process Development at Babcock \& Wilcox}

\section{INL/EXT-11-23166}

Revision 0

March 2012

\section{Approved by:}

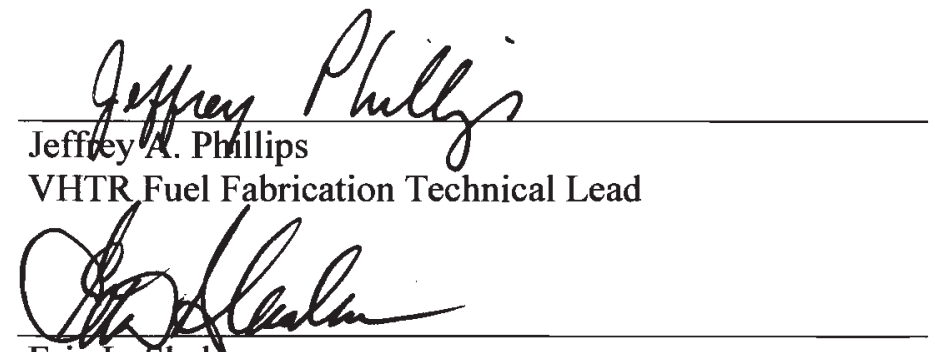

Eric L. Shaber

Fuel Performance and Design
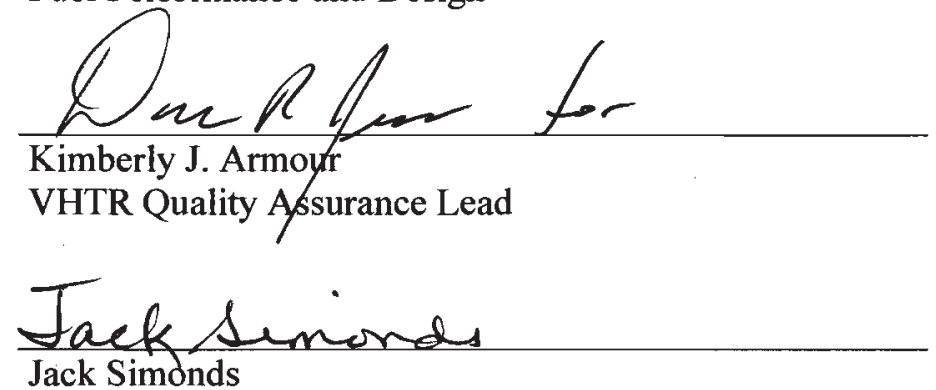

Jack Simonds

Fuel Development and Qualification Project Manager
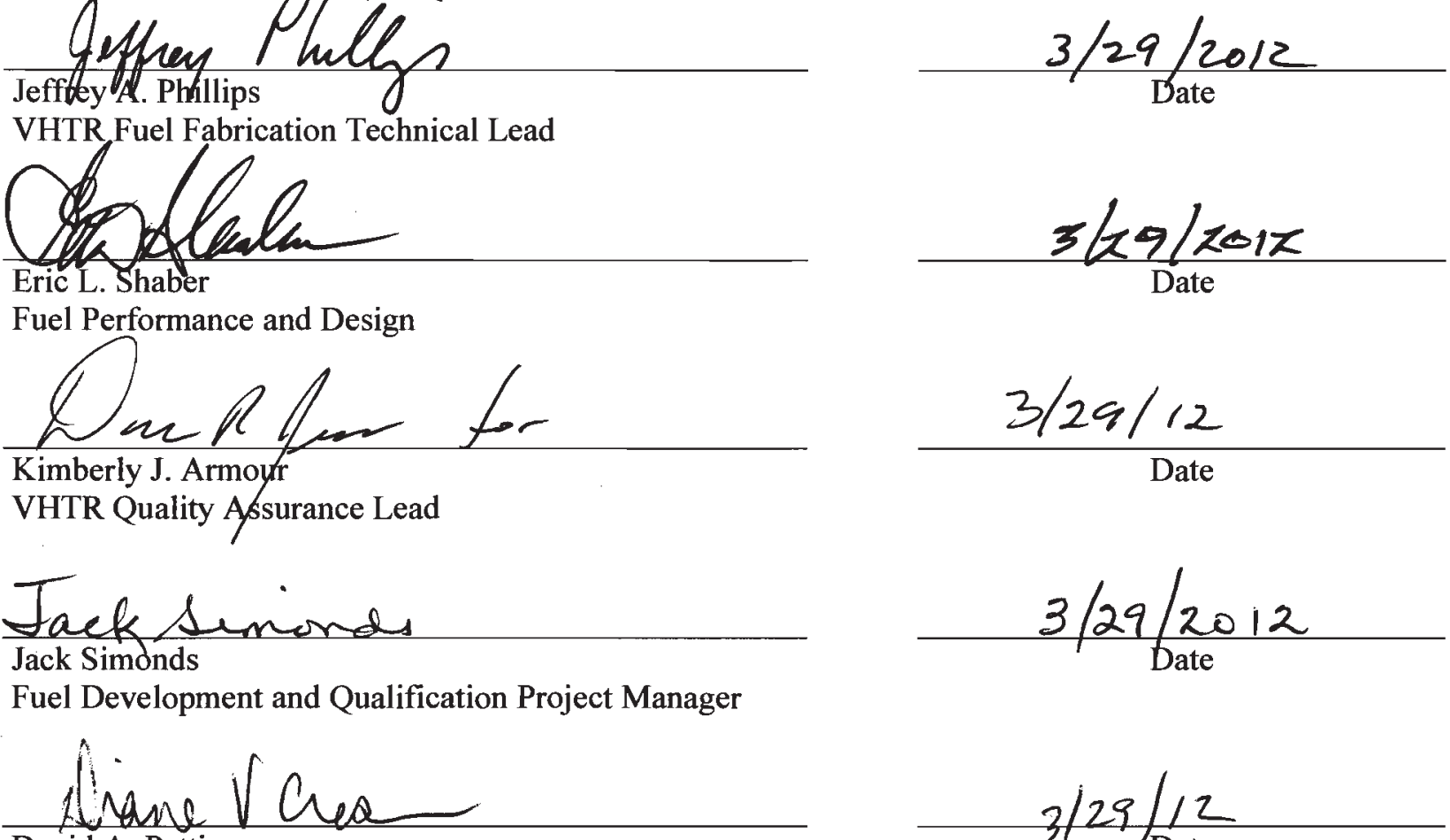

David A. Petti

VHTR TDO Director
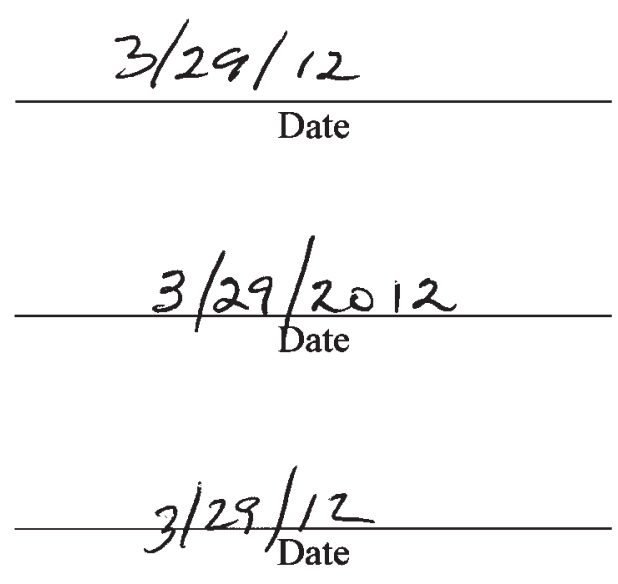



\begin{abstract}
Multiple process approaches have been used historically to manufacture cylindrical nuclear fuel compacts. Scale-up of fuel compacting was required for the Next Generation Nuclear Plant to achieve an economically viable automated production process capable of providing a minimum of 10 compacts per minute with high production yields. In addition, the scale-up effort was required to achieve matrix density equivalent to baseline historical production processes and allow compacting at fuel packing fractions up to $46 \%$ by volume. The scale-up approach of jet milling, fluid-bed overcoating, and hot-press compacting adopted in the U.S. Advanced Gas Reactor (AGR) Fuel Development and Qualification Program involves significant paradigm shifts to capitalize on distinct advantages in simplicity, yield, and elimination of mixed waste. A series of compacting trials have been completed to optimize compacting conditions of time, temperature, and forming pressure using natural uranium oxycarbide (NUCO) fuel at packing fractions exceeding $46 \%$ by volume. Results from these trials are included. The scale-up effort is nearing completion with the process installed and operable using nuclear fuel materials. Final process testing is in progress to certify the process for the manufacture of qualification test fuel compacts in 2012.
\end{abstract}




\section{CONTENTS}

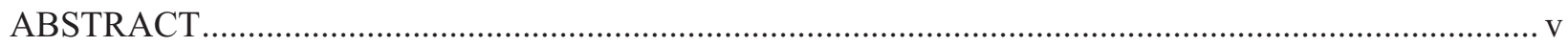

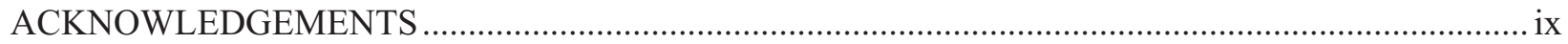

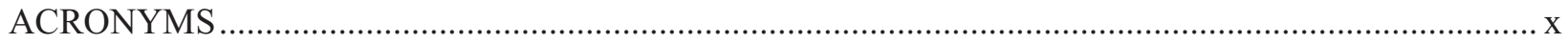

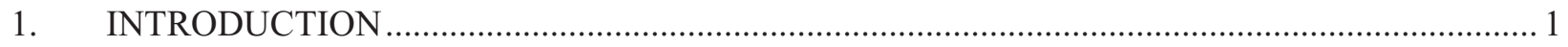

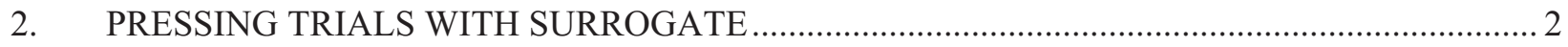

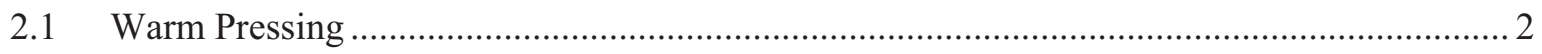

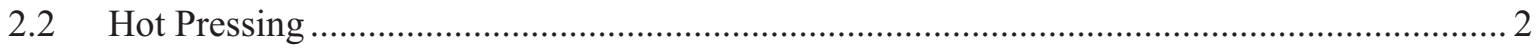

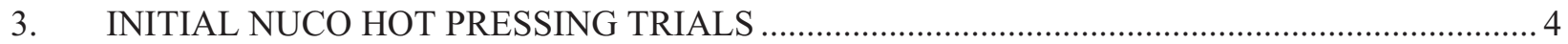

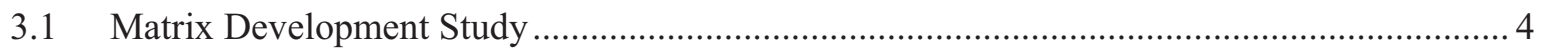

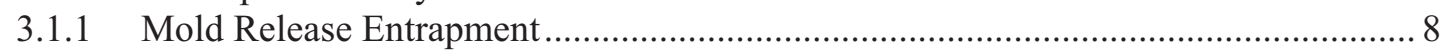

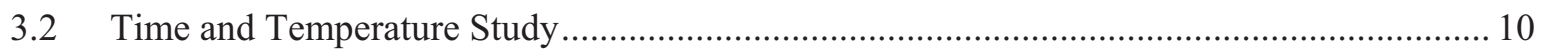

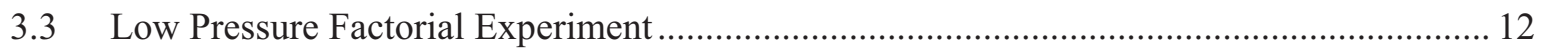

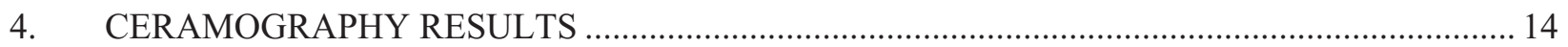

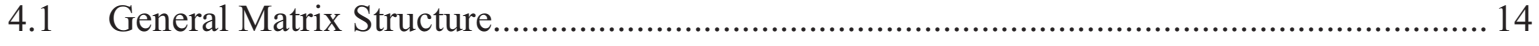

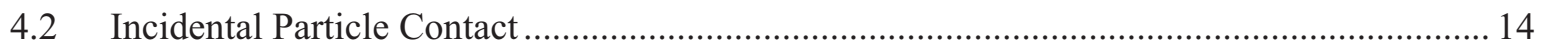

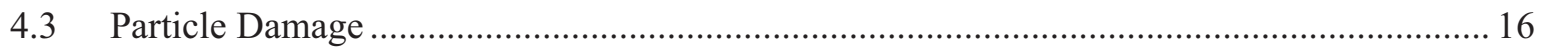

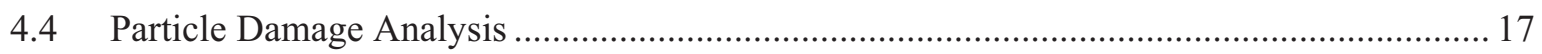

5. FINAL NUCO HOT PRESSING TRIALS-PACKING FRACTION AND PRESSURE

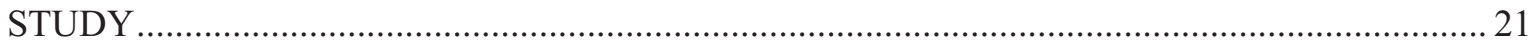

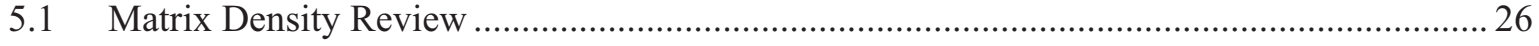

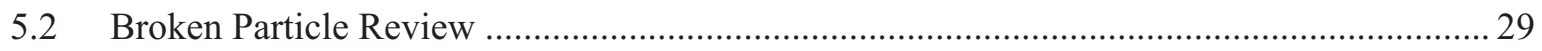

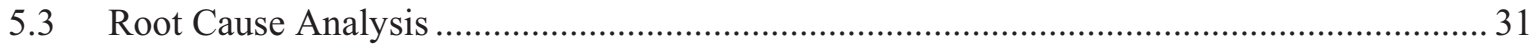

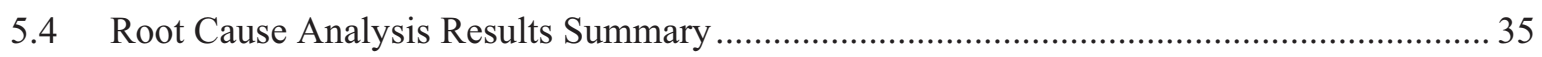

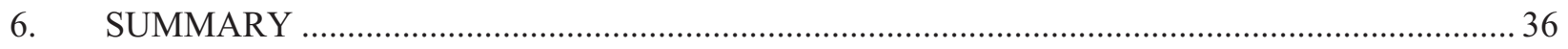

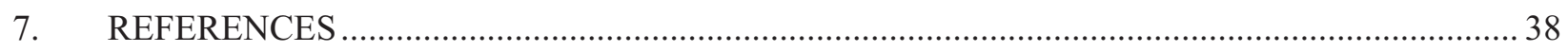

\section{FIGURES}

Figure 1. Photographs of compacts from lots 13013 (top) and 13015 (bottom)..................................... 3

Figure 2. Photos of heat-treated compacts from trials 13046 (left) and 13047 (right), fabricated

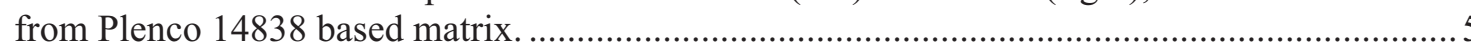

Figure 3. Graph of matrix density as a function of forming conditions used during the matrix finalization study along with the relative significance of the variables. Red is Hexion matrix and blue is Plenco matrix. 
Figure 4. Plot showing the significance of interactions for matrix density from the matrix finalization study.

Figure 5. Graph of packing fraction as a function of forming conditions from the matrix finalization study along with the significance of the variables. Red is Hexion matrix and blue is Plenco matrix.

Figure 6. Plot showing the significance of interactions on packing fraction from the matrix finalization study.

Figure 7. Examples of defects observed in the end faces of NUCO compacts due to mold release entrapment.

Figure 8. Drawing showing mold release application for correct spray application (left), misaligned spray (center), and mold release entrapment in compacting (right).

Figure 9. Photograph of heat treated compacts from lot 13064 pressed at $145^{\circ} \mathrm{C}$ for 220 seconds using proper spray alignment for application of mold release.

Figure 10. Photographs of heat-treated compacts pressed at $175^{\circ} \mathrm{C}$ for 50 seconds (top) and at $168^{\circ} \mathrm{C}$ for 93 seconds (bottom) produced during the time and temperature study at $\mathrm{B} \& \mathrm{~W}$

Figure 11. Graph of compact matrix density analysis as a function of hot pressing temperature and hold time from the central composite design to determine optimal time and temperature set points for matrix density along with the relative significance of the variables and interactions. 12

Figure 12. Photograph of heat treated compacts from lot 13063. 13

Figure 13. Photomicrograph showing matrix structure in a heat treated compact including regions of high and low flow along with an apparent fissure.

Figure 14. Photomicrograph from a NUCO fuel compact showing particle to particle contact in the compact but no particle or TRISO layer damage...

Figure 15. Photomicrograph showing NUCO particles near the surface along the radius (left) and length (right) of selected compacts.

Figure 16. Photomicrograph of deconsolidated particles showing cracks propagating from the kernel into the $\mathrm{SiC}$ layers.

Figure 17. Photomicrograph of a NUCO particle in a compact showing a through-wall crack. Photo on the right is higher magnification of the same crack.

Figure 18. Longitudinal photomicrograph of 13041 showing near close pack loading of fuel particles.

Figure 19. Graph of defect fraction as a function of forming pressure from compact lots pressed from $46 \%$ packing fraction overcoated NUCO lots listed in Table 8.

Figure 20. Graph of estimated compact matrix density as a function of forming pressure for the three different packing fraction cases. .

Figure 21. Graph of compact heat treated mass loss as a function of forming pressure........................2 23

Figure 22. Graph of compact axial shrinkage as a function of forming pressure. .................................. 24

Figure 23. TGA analysis of 5\% HEXA resin matrix during carbonization............................................ 25 
Figure 24. Photographs showing heat treated compacts pressed from targeted 35\% (top), 41\% (center), and 46\% (bottom) packing fraction fuel at $15 \mathrm{MPa}$.

Figure 25. Graph of calculated matrix density as a function of forming pressure for various calculated packing fractions of overcoated NUCO. Points $(\bullet, \mathbf{\square}, \boldsymbol{\Delta})$ represent actual data from $35 \%, 41 \%$, and $46 \%$ packing fraction cases shown in Table 9 and graphed in Figure 20.

Figure 26. Plots showing the significance of forming pressure and packing fraction on matrix density. .28

Figure 27. Graph showing matrix density as a function of packing fraction and forming pressure.

Figure 28. Graph of B\&W measured compact defect failure fraction as a function of forming pressure for 35,41 , and $46 \%$ packing fraction materials compacted at 7,11 , or $15 \mathrm{MPa}$. 30

Figure 29. Photograph of compacts from lot 13091 pressed at $140^{\circ} \mathrm{C}$ and $11 \mathrm{MPa}$ forming pressure. Some compacts pressed at this condition showed pullout from adhesion of the matrix to the punch face.

\section{TABLES}

Table 1. Compaction conditions and results from warm and hot pressing of surrogate $\mathrm{ZrO}_{2}$ TRISO fuel compacts. 2

Table 2. Hot pressing factorial experiment used in initial hot pressing compaction trials. 4

Table 3. Data for estimated matrix density and packing fraction from the matrix finalization test plan. .5

Table 4. Central composite test matrix for hot pressing time/temperature study. 10

Table 5. Estimated compact matrix density and packing fraction data on NUCO compacts collected during temperature and time study at $\mathrm{B} \& \mathrm{~W}$. 11

Table 6. Test parameters for lower pressure study on matrix density and packing fraction. .13

Table 7. Results from lower pressure study. 13

Table 8. Results from fuel particle damage analyses to date. 19

Table 9. Factorial design used for packing fraction and pressure evaluation on NUCO fuel. .21

Table 10. Failed particle results on overcoated NUCO and overcoated NUCO discharged from the hopper. 22

Table 11. Damaged particle results from packing fraction/forming pressure testing. 30

Table 12. Test parameters for lower HEXA and temperature compaction trial at B\&W. 31

Table 13. Compact properties from lower HEXA and temperature compaction trial at B\&W. 33

Table 14. B\&W deconsolidation data from low HEXA and temperature compaction trials. 34 


\section{ACKNOWLEDGEMENTS}

The authors would like to acknowledge the following individuals for their technical work and assistance in performing the tests and collecting the data and documentation necessary to assemble this report:

- Dewayne Husser, Scott Niedzialek, Clay Richardson, Alvin Short, and Brandon Treadway of Babcock \& Wilcox Nuclear Operations Group

- John Hunn and Michael Trammell of Oak Ridge National Laboratory

- Jeff Einerson, Neal MacKay, Doug Marshall, Jack Simonds, and Jodi Vollmer of Idaho National Laboratory. 


\section{ACRONYMS}

AGR Advanced Gas Reactor

AGR-2 Advanced Gas Reactor irradiation test 2

AGR-3/4 Advanced Gas Reactor irradiation tests 3/4

B\&W Babcock and Wilcox Corporation

HEXA Hexamethylenetetramine

INL Idaho National Laboratory

$\mathrm{M}_{\mathrm{m}} \quad$ mass of dry matrix applied in the overcoating process

$\mathrm{M}_{\mathrm{m}}: \mathrm{M}_{\mathrm{p}}$ mass-of- matrix to mass-of-particles ratio

$\mathrm{M}_{\mathrm{p}} \quad$ Mass of fuel particles in the overcoating process

NUCO Natural uranium oxycarbide fuel particles

OPyC outer pyrocarbon layer

ORNL Oak Ridge National Laboratory

PF Packing fraction

SiC Silicon carbide layer

TGA thermogravimetric analysis

TRISO tristructural isotropic

Vol \% volume percent

$\mathrm{ZrO}_{2} \quad$ zirconium dioxide or zirconia 


\section{Compact Process Development at Babcock \& Wilcox}

\section{INTRODUCTION}

Fuel compacting is a process in which individual coated fuel particles are overcoated with a resincontaining graphitic matrix, pressed into a cylindrical shape, thermally cured and carbonized, then heat treated at high temperature. Personnel at Babcock \& Wilcox (B\&W) and Idaho National Laboratory (INL) have been working to develop optimal pressing parameters for overcoated natural uranium oxycarbide (NUCO) fuel particles. The NUCO particles were overcoated with a matrix consisting of natural graphite, synthetic graphite, and a novolac resin. The novolac resins tested during these trials were Hexion SD-1708 and Plenco 14838. All testing used Asbury 3482 natural graphite; SGL Carbon KRB-2000 and Graftech GTI-D synthetic graphites were tested. Compaction trials were initially conducted on overcoated surrogate tristructural-isotropic (TRISO) fuel particles, which consisted of $\mathrm{ZrO}_{2}$ (zirconium dioxide or zirconia) to refine process parameters before switching to overcoated NUCO.

Equipment and technology upgrades for AGR fuel overcoating and compacting were completed in 2010 and presented in 2010 and 2011. ${ }^{1,2}$ Initial finalization planning was performed and documented in PLN-3755, "Compacting Scale-up Process - Detailed Test Results and Finalization Plan."3 This plan focuses on providing a complete finalization plan that performed all the testing desirable to get a complete picture of both hot and warm press compacting with multiple sources of materials. Final planning is documented in PLN-2908, "AGR Fuel Development Compacting Scale-Up Plan"4 which describes testing, data collection, and analyses for this report.

Compaction trials with surrogate material evaluated warm pressing $\left(80\right.$ to $\left.100^{\circ} \mathrm{C}\right)$ and hot pressing $\left(145\right.$ to $195^{\circ} \mathrm{C}$ ) to evaluate the compact matrix density as a function of pressing conditions. INL designed a factorial experiment for warm and hot pressing of NUCO. Warm pressing evaluated matrix at two levels and temperature at three levels. This required a total of six experimental trials $(2 \times 3$ factorial $)$ to complete. Hot pressing evaluated matrix at two levels, temperature at three levels, and pressure at two levels, requiring a total of 12 experiments $(2 \times 3 \times 2$ factorial $)$.

Follow-up compaction trials were performed to independently evaluate the effects of time and temperature. These trials used a central composite test matrix with attributes of matrix density and packing fraction being measured as a function of hot pressing temperature and time at temperature. Finally, B\&W performed a final hot pressing factorial experiment evaluating lower forming pressures (10 and $14 \mathrm{MPa})$ at three different hot pressing temperatures requiring six experimental trials $(2 \times 3$ factorial $)$ with matrix density and packing fraction being measured on these NUCO containing compacts.

Fuel particle damage analytical results from the early test matrices prompted two additional sets of compacting tests designed to determine the source of particle damage found in test matrix compact samples. The first of these, the "Fuel Damage Test," initially indicated particle damage across the full process space. A second set of tests, the "Low HEXA Tests," was then performed to evaluate an even broader process space using only 5\% HEXA with the resin. It was ultimately shown that part of the particle damage reported was the direct result of faulty analytical methods, but that compacting above 45 volume percent (vol \%) packing fraction (PF) may not be feasible. 


\section{PRESSING TRIALS WITH SURROGATE}

\subsection{Warm Pressing}

For warm pressing compaction trials, $\mathrm{B} \& \mathrm{~W}$ pressed 236 compacts using three test conditions as shown in Table 1. Surrogate $\mathrm{ZrO}_{2}$-fuel TRISO fuel particles were overcoated with Plenco 14838-based matrix using a mass to target a $1.75 \mathrm{~g} / \mathrm{cm}^{3}$ matrix density at $46 \%$ packing fraction. Compacts were pressed from this material at 80,90 , and $100^{\circ} \mathrm{C}$. Compacts were measured in the green condition and then carbonized, heat treated, and re-measured. Matrix density and packing fraction were estimated using the average $\mathrm{ZrO}_{2}$ particle weight and diameter along with the overcoating mass-of- matrix to mass-ofparticles ratio $\left(\mathrm{M}_{\mathrm{m}}: \mathrm{M}_{\mathrm{p}}\right)$. In all three conditions, the estimated matrix density was well below the targeted matrix density of $1.75 \mathrm{~g} / \mathrm{cm}^{3}$. There is a noted increase in matrix density with increasing temperature, but the increase is not adequate to achieve the desired level. Based on these results, it was decided to abandon warm pressing of NUCO, as higher temperatures and/or higher forming pressures would be needed to reach the $1.75 \mathrm{~g} / \mathrm{cm}^{3}$ level.

Table 1. Compaction conditions and results from warm and hot pressing of surrogate $\mathrm{ZrO}_{2}$ TRISO fuel compacts.

\begin{tabular}{|c|c|c|c|c|c|c|c|}
\hline Type & Lot & Matrix & $\begin{array}{c}\text { Temperature } \\
\left({ }^{\circ} \mathrm{C}\right)\end{array}$ & $\begin{array}{l}\text { Hold Time } \\
\text { (seconds) }\end{array}$ & $\begin{array}{c}\text { Pressure } \\
(\mathrm{MPa})\end{array}$ & $\begin{array}{c}\text { Est. Matrix } \\
\text { Density* } \\
\left(\mathrm{g} / \mathrm{cm}^{3}\right)\end{array}$ & $\begin{array}{c}\text { Est. Packing } \\
\text { Fraction* } \\
(\%)\end{array}$ \\
\hline \multirow{3}{*}{$\begin{array}{l}\text { Warm } \\
\text { Pressing }\end{array}$} & 13002 & Plenco 14838 & 100 & 200 & 21.8 & 1.50 & 39.0 \\
\hline & 13003 & Plenco 14838 & 80 & 200 & 21.8 & 1.38 & 37.0 \\
\hline & 13005 & Plenco 14838 & 90 & 200 & 21.8 & 1.44 & 38.1 \\
\hline \multirow{11}{*}{$\begin{array}{l}\text { Hot } \\
\text { Pressing }\end{array}$} & 13001 & Plenco 14838 & 165 & 60 & 18.1 & 1.66 & 40.7 \\
\hline & 13008 & Plenco 14838 & 140 & 60 & 18.1 & 1.60 & 39.8 \\
\hline & 13009 & Plenco 14838 & 150 & 60 & 18.1 & 1.60 & 39.8 \\
\hline & 13010 & Plenco 14838 & 160 & 60 & 18.1 & 1.63 & 40.4 \\
\hline & 13012 & Plenco 14838 & 165 & 60 & 18.1 & 1.71 & 47.5 \\
\hline & 13013 & Plenco 14838 & 165 & 90 & 18.1 & 1.73 & 47.8 \\
\hline & 13014 & Plenco 14838 & 175 & 45 & 18.1 & 1.72 & 47.6 \\
\hline & 13015 & Plenco 14838 & 175 & 60 & 18.1 & 1.72 & 47.7 \\
\hline & 13016 & Plenco 14838 & 165 & 120 & 18.1 & 1.71 & 47.6 \\
\hline & 13017 & Plenco 14838 & 185 & 30 & 18.1 & 1.72 & 47.6 \\
\hline & 13018 & Plenco 14838 & 195 & 30 & 18.1 & 1.71 & 47.6 \\
\hline
\end{tabular}

\subsection{Hot Pressing}

For hot-pressing compaction trials, B\&W pressed 240 compacts using a range of temperatures and pressures as shown in Table 1. Surrogate $\mathrm{ZrO}_{2}$-fuel TRISO fuel particles were overcoated with Plenco 14838-based matrix using a thickness to target $1.75 \mathrm{~g} / \mathrm{cm}^{3}$ matrix density and packing fractions of 40 and $46 \%$. Compacts were pressed, carbonized, heat treated, and measured to calculate shrinkage and 
compact density. This information, combined with measurements in the green condition, allowed for estimation of packing fraction and matrix density.

The initial results with hot pressing showed improved matrix density, but results were still lower than the targeted level (refer to Table 1). Follow-up compaction testing yielded improved results and provided the baseline for establishing test parameters with NUCO. These results provide confirmation of the temperatures required for rapid hot pressing with novolac-based resins, where temperatures in excess of $110^{\circ} \mathrm{C}$ are necessary to fully soften the resin. Photographs of surrogate compacts are shown in Figure 1. Some surface texture is evident on the compacts resulting from shrinkage of the matrix during heat treatment. These compacts each contain about 5,000 surrogate fuel particles.
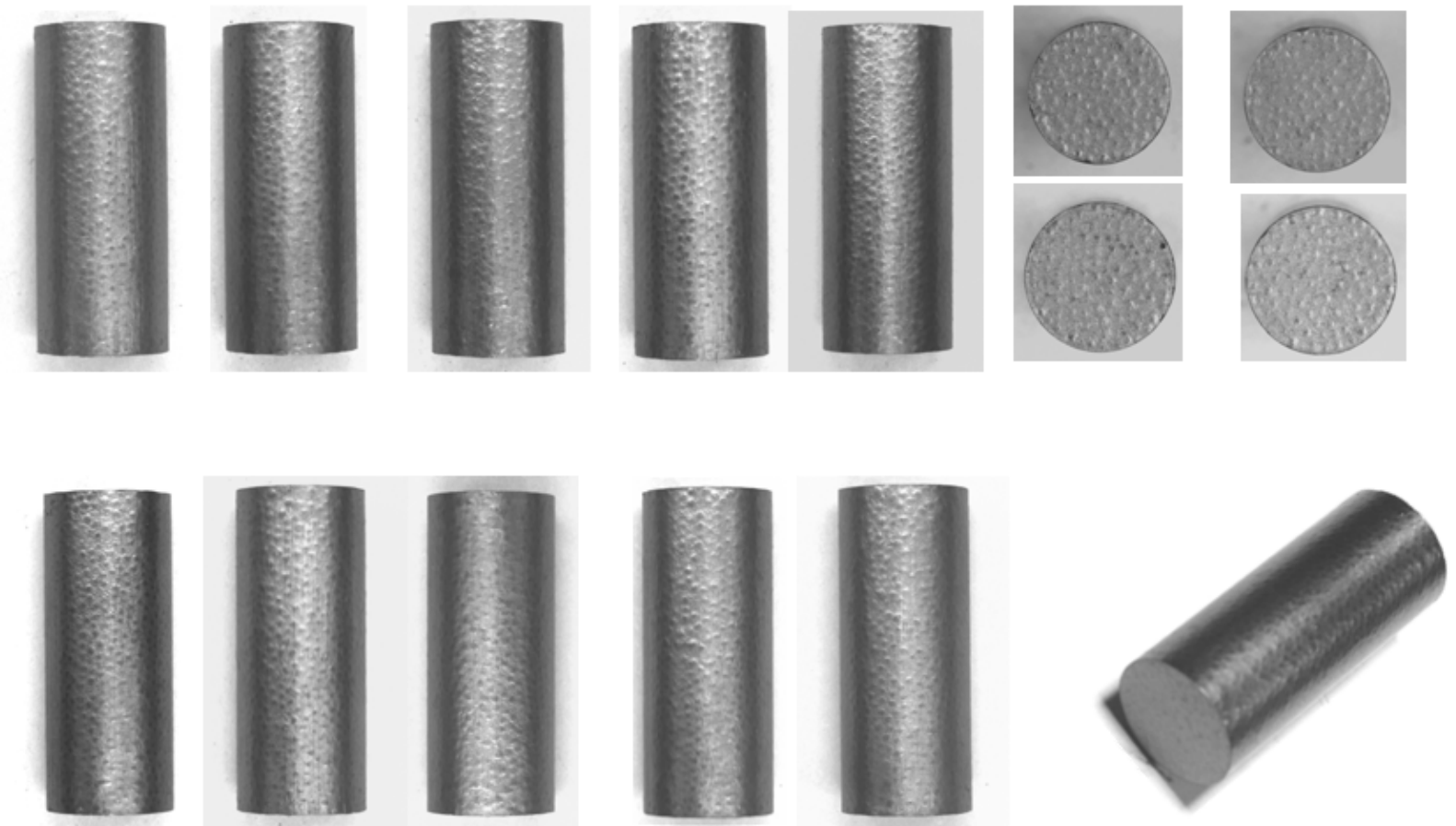

Figure 1. Photographs of compacts from lots 13013 (top) and 13015 (bottom). 


\section{INITIAL NUCO HOT PRESSING TRIALS}

\subsection{Matrix Development Study}

INL completed and issued PLN-3818, "Finalization Test Matrix and Plan - Compact Scale-up," on June 20, 2011. ${ }^{5}$ This report provides detailed summary plans for compaction scale-up activities and efforts at $\mathrm{B} \& \mathrm{~W}$. The plan for hot-press compaction testing was a $2 \times 3 \times 2$ factorial experiment as shown in Table 2.

$\mathrm{B} \& \mathrm{~W}$ initiated the compaction scale-up effort with preparation of a composite lot of NUCO fuel particles. B\&W completed leach-burn-leach analysis on individual batches of NUCO fuel particles and blended these batches into a $15 \mathrm{~kg}$ composite NUCO lot. B\&W pulled a sample of the composite lot to provide a baseline for leach-burn-leach. B\&W completed overcoating trials during the week of May 23, 2011, and began hot press compaction and heat treatment trials during the week of May 31, 2011, per the experiment design shown in Table 2.

Table 2. Hot pressing factorial experiment used in initial hot pressing compaction trials.

\begin{tabular}{|c|l|c|c|c|c|}
\hline Lot & \multicolumn{1}{|c|}{ Matrix } & $\begin{array}{c}\text { Packing Fraction } \\
(\%)\end{array}$ & $\begin{array}{c}\text { Temperature } \\
\left({ }^{\circ} \mathrm{C}\right)\end{array}$ & $\begin{array}{c}\text { Hold Time } \\
(\text { seconds })\end{array}$ & $\begin{array}{c}\text { Pressure } \\
(\mathrm{MPa})\end{array}$ \\
\hline 13036 & Hexion SD-1708 & 46 & 145 & 220 & 16 \\
\hline 13037 & Hexion SD-1708 & 46 & 145 & 220 & 20 \\
\hline 13038 & Hexion SD-1708 & 46 & 160 & 90 & 16 \\
\hline 13039 & Hexion SD-1708 & 46 & 160 & 90 & 20 \\
\hline 13040 & Hexion SD-1708 & 46 & 190 & 40 & 16 \\
\hline 13041 & Hexion SD-1708 & 46 & 190 & 40 & 20 \\
\hline 13058 & Plenco 14838 & 46 & 145 & 220 & 16 \\
\hline 13043 & Plenco 14838 & 46 & 145 & 220 & 20 \\
\hline 13044 & Plenco 14838 & 46 & 160 & 90 & 16 \\
\hline 13045 & Plenco 14838 & 46 & 160 & 90 & 20 \\
\hline 13046 & Plenco 14838 & 46 & 190 & 40 & 16 \\
\hline 13047 & Plenco 14838 & 46 & 190 & 40 & 20 \\
\hline
\end{tabular}

The initial run of the factorial experiment was determined unacceptable for statistical analysis because of a nitrogen spring pressure issue that prevented adequate balancing of the force applied to each compact. The issue was investigated and corrected, new material was overcoated, and the factorial experiment was repeated in July. Matrix density and packing fraction results from the heat treated compacts from the July test are shown in Table 3, and photographs of heat-treated compacts are shown in Figure 2. 
Table 3. Data for estimated matrix density and packing fraction from the matrix finalization test plan.

\begin{tabular}{|c|c|c|c|c|c|c|}
\hline Lot & Matrix & $\begin{array}{c}\text { Temperature } \\
\left({ }^{\circ} \mathrm{C}\right)\end{array}$ & $\begin{array}{c}\text { Hold Time } \\
(\text { seconds })\end{array}$ & $\begin{array}{c}\text { Pressure } \\
(\mathrm{MPa})\end{array}$ & $\begin{array}{c}\text { Est. Matrix } \\
\text { Density }\left(\mathrm{g} / \mathrm{cm}^{3}\right)\end{array}$ & $\begin{array}{c}\text { Est. Packing } \\
\text { Fraction }(\%)\end{array}$ \\
\hline 13036 & Hexion SD-1708 & 145 & 220 & 16 & 1.73 & 46.9 \\
\hline 13037 & Hexion SD-1708 & 145 & 220 & 20 & 1.73 & 46.9 \\
\hline 13038 & Hexion SD-1708 & 160 & 90 & 16 & 1.74 & 47.0 \\
\hline 13039 & Hexion SD-1708 & 160 & 90 & 20 & 1.74 & 47.1 \\
\hline 13040 & Hexion SD-1708 & 190 & 40 & 16 & 1.76 & 47.3 \\
\hline 13041 & Hexion SD-1708 & 190 & 40 & 20 & 1.75 & 47.2 \\
\hline 13058 & Plenco 14838 & 145 & 220 & 16 & 1.72 & 46.8 \\
\hline 13043 & Plenco 14838 & 145 & 220 & 20 & 1.72 & 46.9 \\
\hline 13044 & Plenco 14838 & 160 & 90 & 16 & 1.73 & 47.0 \\
\hline 13045 & Plenco 14838 & 160 & 90 & 20 & 1.73 & 47.1 \\
\hline 13046 & Plenco 14838 & 190 & 40 & 16 & 1.74 & 47.2 \\
\hline 13047 & Plenco 14838 & 190 & 40 & 20 & 1.75 & 47.3 \\
\hline
\end{tabular}
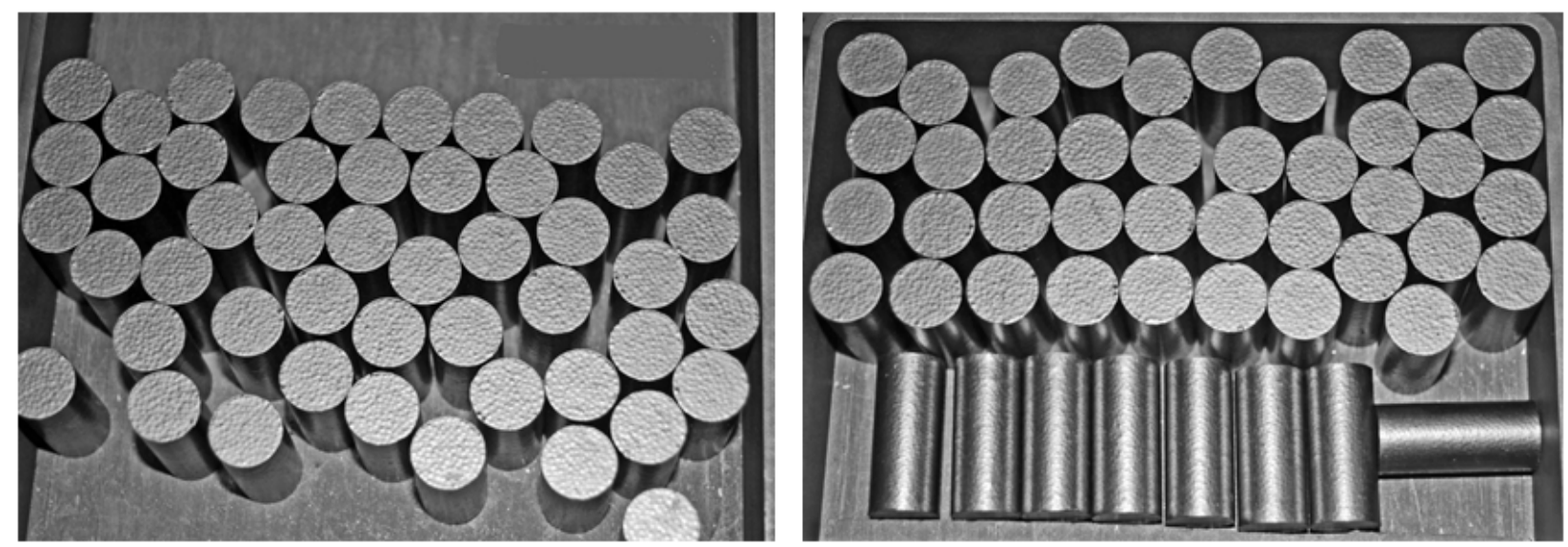

Figure 2. Photos of heat-treated compacts from trials 13046 (left) and 13047 (right), fabricated from Plenco 14838 based matrix.

INL completed statistical data analyses for matrix density and packing fraction on the NUCO compacts pressed in July 2011. Matrix-density data analysis is shown in Figure 3, and the effect of the interactions is shown in Figure 4. Packing-fraction data analysis is shown in Figure 5, and the effect of the interactions between the variables is shown Figure 6. All variables and interactions for matrix density with the exception of forming pressure were significant at a $95 \%$ confidence level, Temperature was the most significant variable, as indicated in Figure 3, and dominated all other variables and interactions by a considerable margin as increases in hot-pressing temperature resulted in an increase in matrix density. Also of interest is the significance of the matrix, with Hexion SD-1708 resin with SGL KBR-2000 synthetic graphite producing higher matrix densities than Plenco 14838 resin with GrafTech GP-60 synthetic graphite. Both, however, produced compacts with matrix density at the targeted level. The role of interactions can be seen in Figure 4, particularly with nonparallel lines, intersecting lines, and parabolic curves. Resin-pressure, resin-temperature, and resin-temperature-pressure displayed the largest significance over the range of variables tested in this activity. 


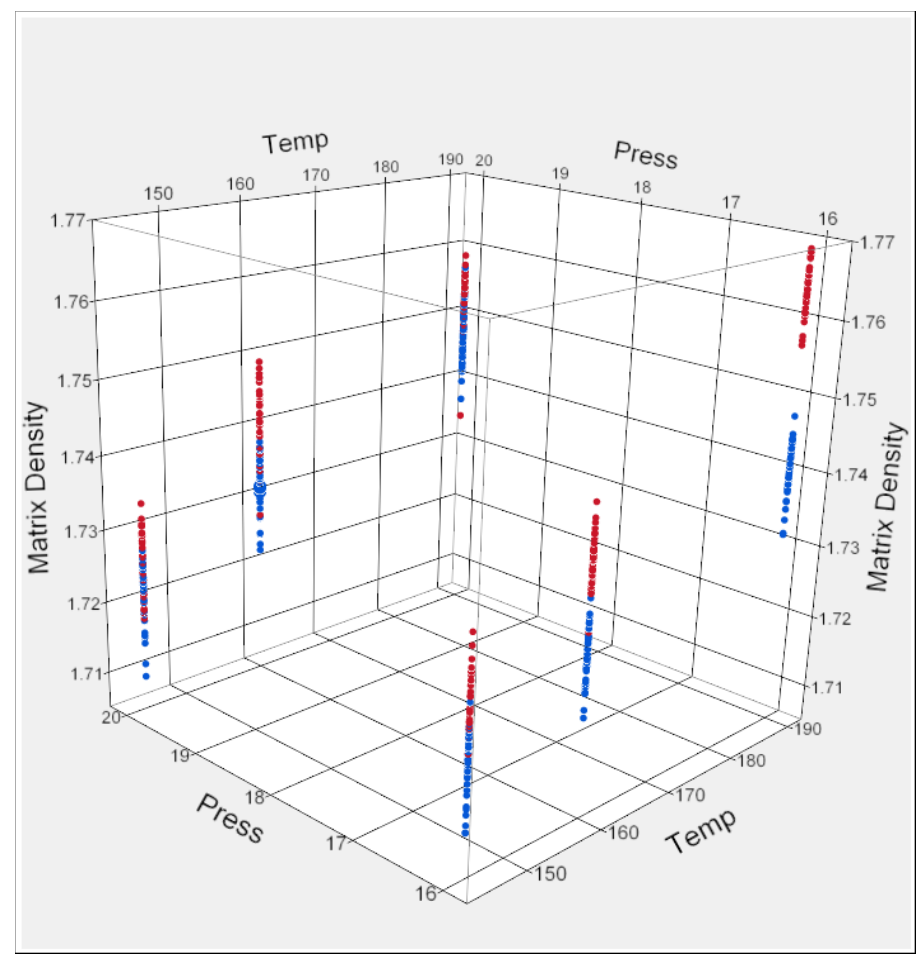

\begin{tabular}{|c|c|c|}
\hline Parameter & tratio & Significance \\
\hline Temperature & 60.78 & i : \\
\hline Resin & -29.50 & 1. \\
\hline Resin ${ }^{*}$ Pressure & 12.81 & $\vdots$ \\
\hline Resin*Temp & -10.27 & $\begin{array}{lll}1 & 1 & 1 \\
1 & 1 & 1\end{array}$ \\
\hline Resin ${ }^{*}$ Temp $p^{*}$ Press & 10.03 & ; \\
\hline Temperature ${ }^{2}$ & -6.08 & ' \\
\hline Temp*Press & -4.66 & ' \\
\hline Pressure & 1.61 & 1 \\
\hline
\end{tabular}

Figure 3. Graph of matrix density as a function of forming conditions used during the matrix finalization study along with the relative significance of the variables. Red is Hexion matrix and blue is Plenco matrix.

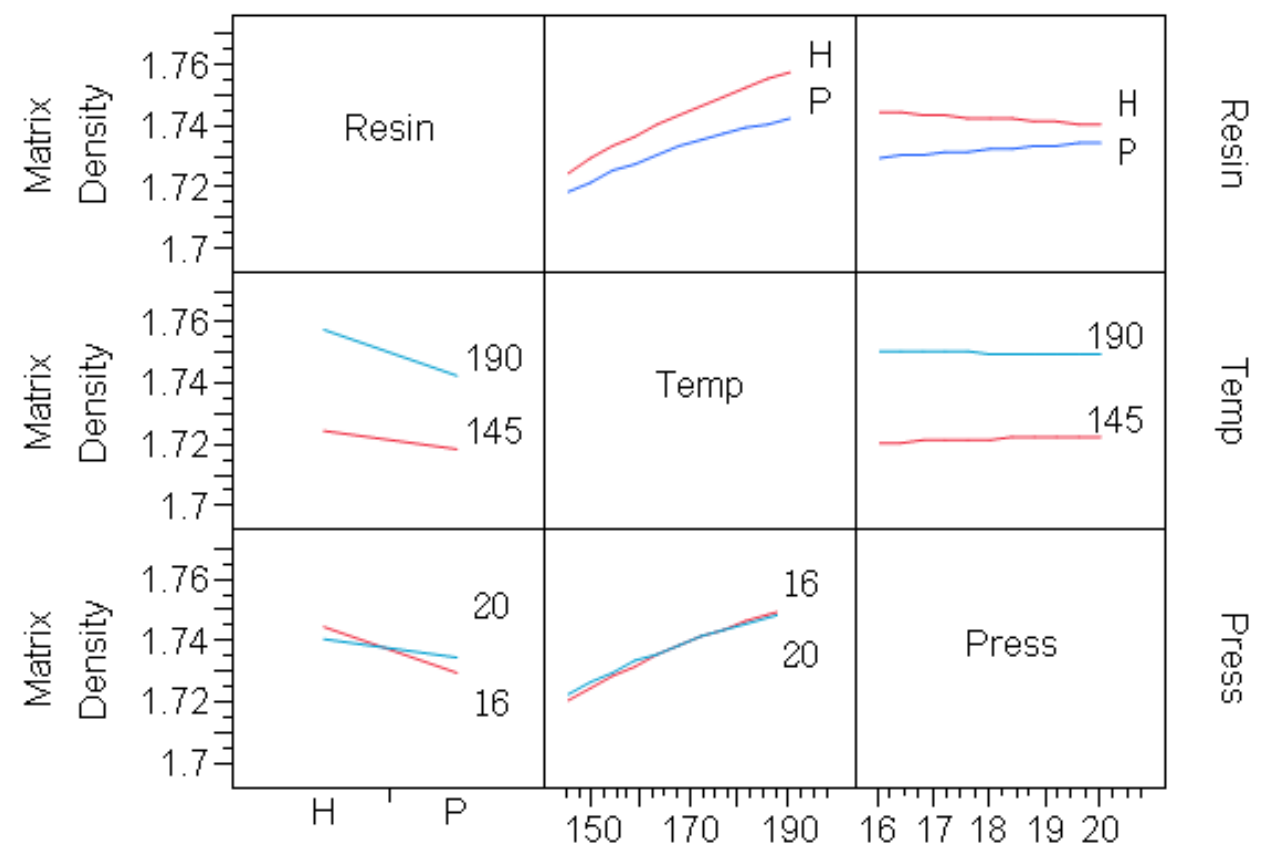

Figure 4. Plot showing the significance of interactions for matrix density from the matrix finalization study. 


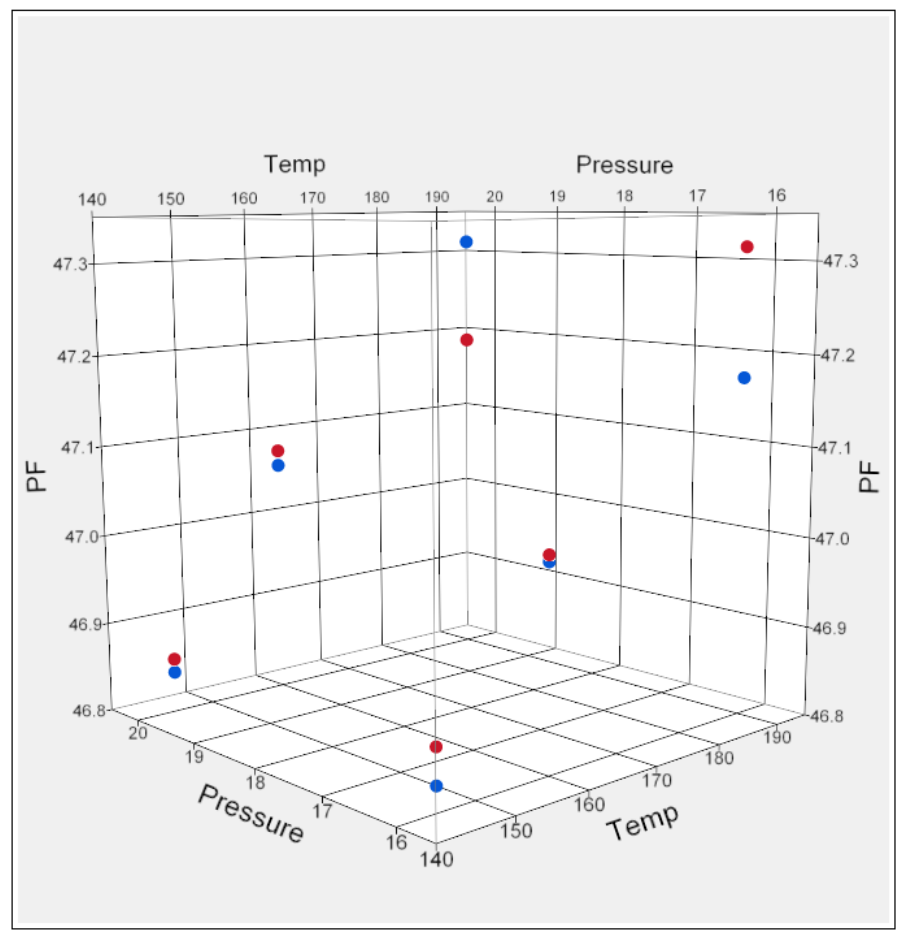

\begin{tabular}{|c|c|c|c|c|}
\hline Parameter & tratio & \multicolumn{3}{|c|}{ Significance } \\
\hline Temperature & 15.72 & i : & & \\
\hline Temperature $^{2}$ & -3.10 & $1:$ & & \\
\hline Resin ${ }^{*}$ Temp*Press & -2.86 & . ' ' & & \\
\hline Resin ${ }^{*}$ Press & -2.40 & 11 & & 1 \\
\hline Pressure & 1.09 & 1,1 & & \\
\hline Resin & 0.82 & : & & \\
\hline Resin ${ }^{*} T e m p$ & -0.35 & 1 & & \\
\hline Temp*Press & -0.20 & $\begin{array}{l:l}1 & 1 \\
1 & 1\end{array}$ & & 1 \\
\hline
\end{tabular}

Figure 5. Graph of packing fraction as a function of forming conditions from the matrix finalization study along with the significance of the variables. Red is Hexion matrix and blue is Plenco matrix.

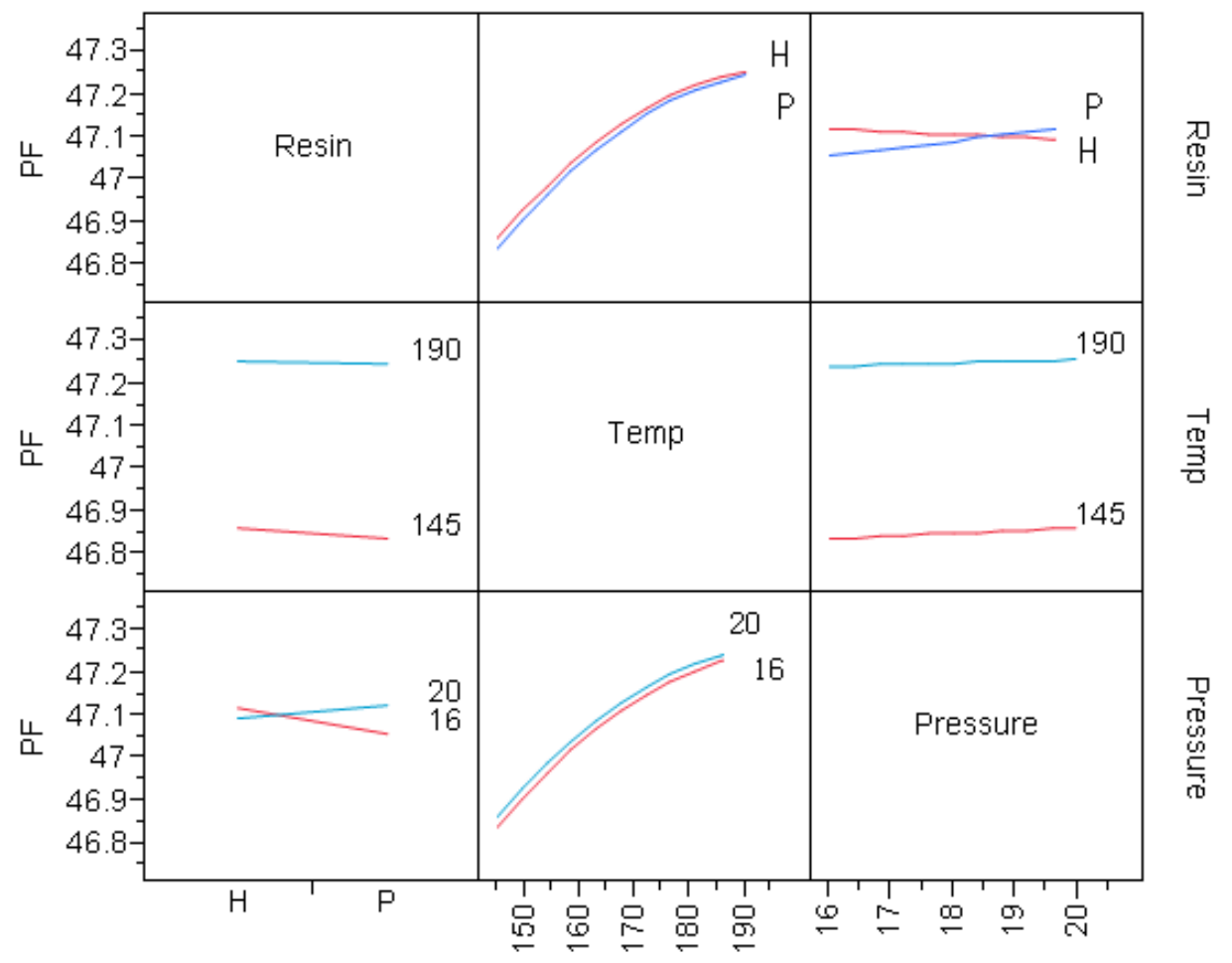

Figure 6. Plot showing the significance of interactions on packing fraction from the matrix finalization study. 
As indicated in Figure 5, temperature once again dominated all other variables and interactions for packing fraction. Temperature and temperature squared were both significant at a $95 \%$ confidence level, increasing temperature producing higher packing fractions. Still, all temperature set points produced compacts that had high packing fractions. The role of interactions can be seen in Figure 6, with resintemperature-pressure having the highest degree of significance. This is suspected to be the case because of the apparent flip in data points between Hexion- and Plenco-based compacts pressed at 16 and $20 \mathrm{MPa}$ and $190^{\circ} \mathrm{C}$ as shown in Figure 5, where the Hexion matrix yielded a higher matrix density at $16 \mathrm{MPa}$ but the Plenco matrix had the greater value at $20 \mathrm{MPa}$.

\subsubsection{Mold Release Entrapment}

In preparing compacts for the matrix finalization study, some compacts were observed to have defects on the end faces as shown in Figure 7. The appearance of these defects was only observed after the compacts had been heat treated, being more prevalent on the lower temperature compacts $\left(145^{\circ} \mathrm{C}\right)$ and practically nonexistent on the higher temperature compacts $\left(160\right.$ and $\left.190^{\circ} \mathrm{C}\right)$. The nature of the defects was thought to be caused by misalignment of mold release spray nozzles and/or inadequate evaporation of the liquid carrier prior to compaction, resulting in pooling of mold release at corners of the die and on the punch face as shown in Figure 8.
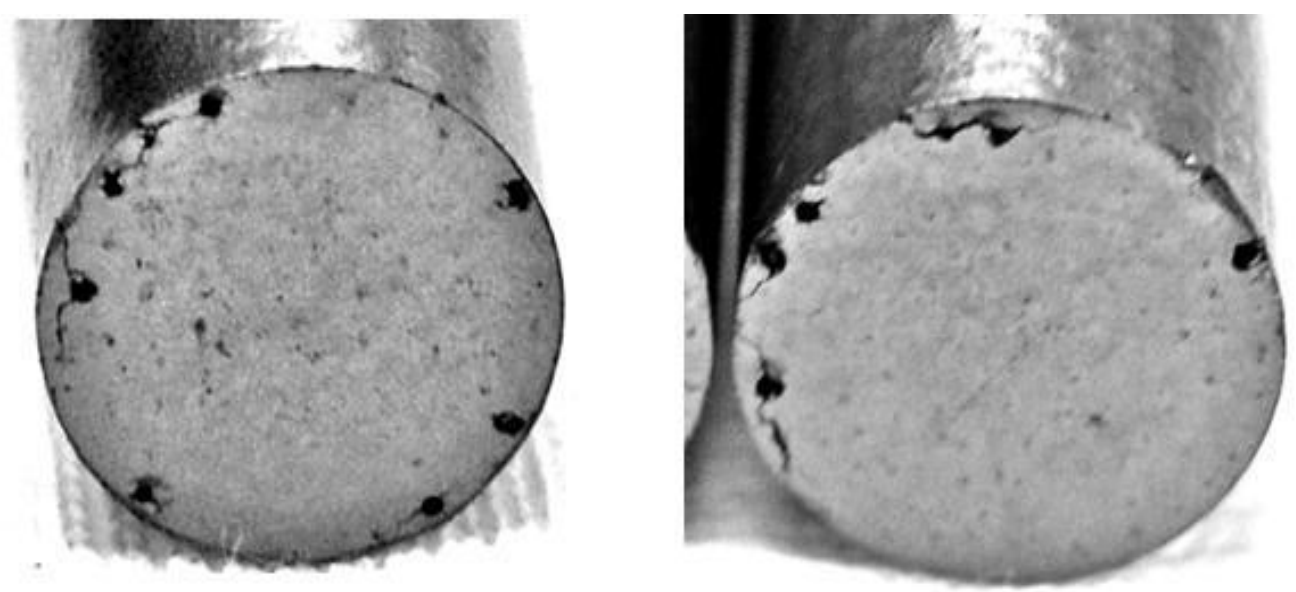

Figure 7. Examples of defects observed in the end faces of NUCO compacts due to mold release entrapment. 

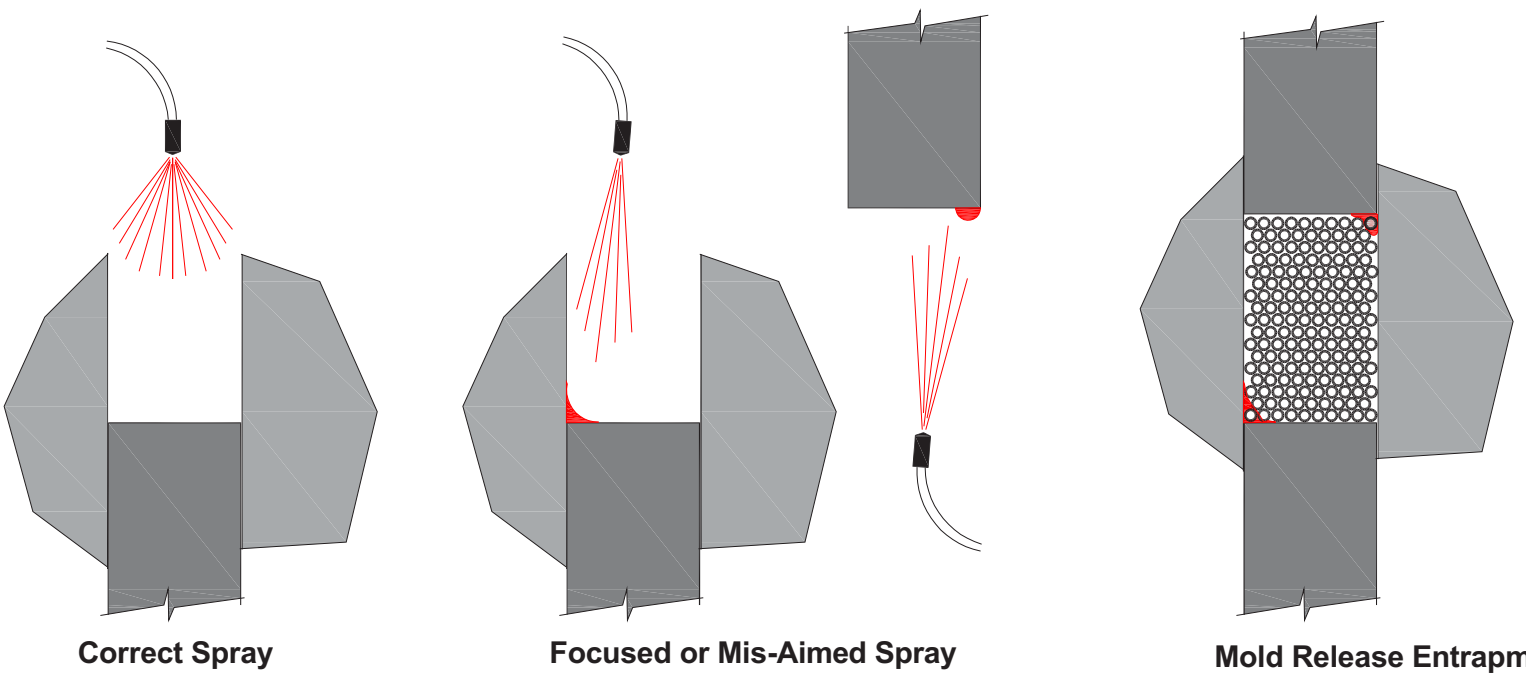

Mold Release Entrapment

Figure 8. Drawing showing mold release application for correct spray application (left), misaligned spray (center), and mold release entrapment in compacting (right).

During the compaction process, a mold release (Michem ${ }^{\circledR}$ Emulsion 52137) is applied to the die walls and punch faces after each compaction cycle. This mold release is a nonionic polyethylene wax diluted 10:1 with water. This provides a lubricant to the die walls and punch faces that reduces friction between the overcoated particles and the die cavity during compaction and aids in part release. When these defects were observed after heat treatment, $\mathrm{B} \& \mathrm{~W}$ implemented corrective action to better align the spray nozzles and reduce the volume of liquid applied. Both of these adjustments reduced the potential for liquid pooling; these defects were not observed in samples produced in subsequent hot press compaction trials as shown in Figure 9.

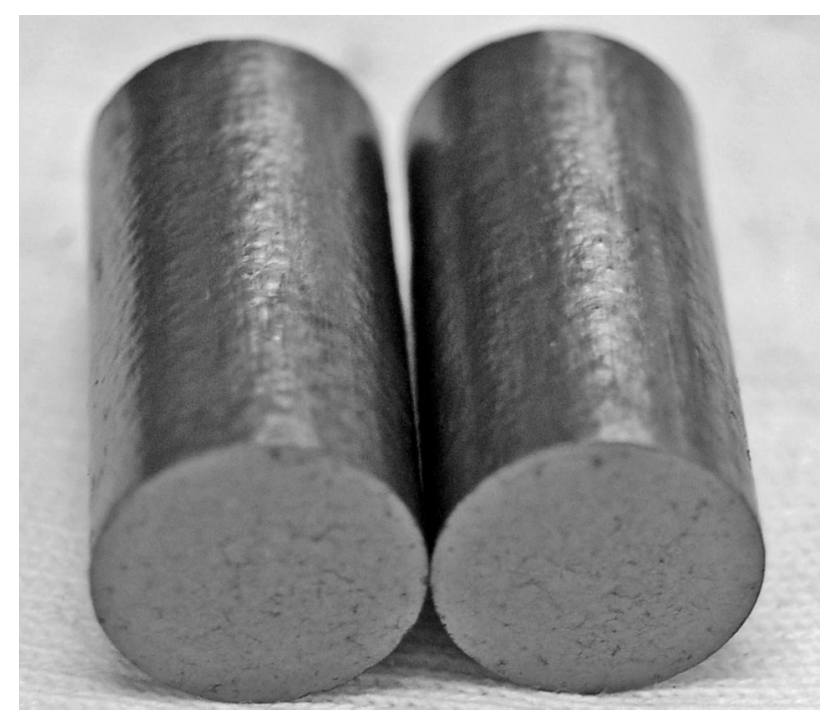

Figure 9. Photograph of heat treated compacts from lot 13064 pressed at $145^{\circ} \mathrm{C}$ for 220 seconds using proper spray alignment for application of mold release. 


\subsection{Time and Temperature Study}

Time at temperature was not evaluated as a variable for the factorial design. This was thought to have an influence on the compact density and quality as a function of temperature. Based on the trial testing, INL designed a central composite test to evaluate time and temperature as independent variables. The test design is shown in Table 4 . B\&W completed a series of compaction experiments to evaluate hot-pressing temperature and time at temperature. The goal was to identify optimal time and temperature set points with the output being matrix density and compact shrinkage. B\&W pressed 20 compacts per condition using the central composite design shown in Table 5. Compacts were measured in the green condition, then carbonized and heat treated. Final measurements were obtained on the heat-treated compacts, which allowed calculation of the estimated matrix density and packing fraction.

INL completed data analysis of matrix density based on the results of the trial by evaluating time, temperature, and the interactions on matrix density and packing fraction. The test results are shown in Table 5, with selected compacts shown in Figure 10. The matrix density and packing fraction on each set of compacts were within the targeted region, indicating that the processing envelope is fairly wide, at least over the range of temperatures and times tested. Figure 11 shows the contour map of matrix density over the range of test conditions. All variables and interactions were significant at a $95 \%$ confidence level, with temperature square and time square having the greatest degree of significance as shown in Figure 11. From these data, the maximum in matrix density for a $46 \%$ packing fraction is predicted to occur at a hotpressing temperature of approximately $177^{\circ} \mathrm{C}$ and a hold time at temperature of about 68 seconds. These conditions were verified at $\mathrm{B} \& \mathrm{~W}$ in follow-up testing on NUCO compacts.

Table 4. Central composite test matrix for hot pressing time/temperature study.

\begin{tabular}{|c|c|c|c|c|c|}
\hline Lot & Matrix & $\begin{array}{c}\text { Packing Fraction } \\
(\%)\end{array}$ & $\begin{array}{c}\text { Pressure } \\
(\mathrm{MPa})\end{array}$ & $\begin{array}{c}\text { Temperature } \\
\left({ }^{\circ} \mathrm{C}\right)\end{array}$ & $\begin{array}{c}\text { Hold Time } \\
(\text { seconds })\end{array}$ \\
\hline 13049 & Hexion SD-1708 & 46 & 20 & 165 & 75 \\
\hline 13050 & Hexion SD-1708 & 46 & 20 & 168 & 93 \\
\hline 13051 & Hexion SD-1708 & 46 & 20 & 168 & 57 \\
\hline 13052 & Hexion SD-1708 & 46 & 20 & 175 & 100 \\
\hline 13053 & Hexion SD-1708 & 46 & 20 & 175 & 75 \\
\hline 13054 & Hexion SD-1708 & 46 & 20 & 175 & 50 \\
\hline 13055 & Hexion SD-1708 & 46 & 20 & 182 & 93 \\
\hline 13056 & Hexion SD-1708 & 46 & 20 & 182 & 57 \\
\hline 13057 & Hexion SD-1708 & 46 & 20 & 185 & 75 \\
\hline
\end{tabular}


Table 5. Estimated compact matrix density and packing fraction data on NUCO compacts collected during temperature and time study at B\&W.

\begin{tabular}{|c|c|c|c|c|}
\hline Lot & $\begin{array}{c}\text { Temperature } \\
\left({ }^{\circ} \mathrm{C}\right)\end{array}$ & $\begin{array}{c}\text { Hold Time } \\
(\text { seconds })\end{array}$ & $\begin{array}{c}\text { Est. Matrix } \\
\text { Density }\left(\mathrm{g} / \mathrm{cm}^{3}\right)\end{array}$ & $\begin{array}{c}\text { Est. Packing } \\
\text { Fraction }(\%)\end{array}$ \\
\hline 13049 & 165 & 75 & 1.74 & 47.8 \\
\hline 13050 & 168 & 93 & 1.74 & 47.9 \\
\hline 13051 & 168 & 57 & 1.74 & 47.9 \\
\hline 13052 & 175 & 100 & 1.74 & 47.9 \\
\hline 13053 & 175 & 75 & 1.75 & 47.8 \\
\hline 13054 & 175 & 50 & 1.75 & 47.8 \\
\hline 13055 & 182 & 93 & 1.74 & 47.9 \\
\hline 13056 & 182 & 57 & 1.75 & 47.8 \\
\hline 13057 & 185 & 75 & 1.75 & 47.9 \\
\hline
\end{tabular}

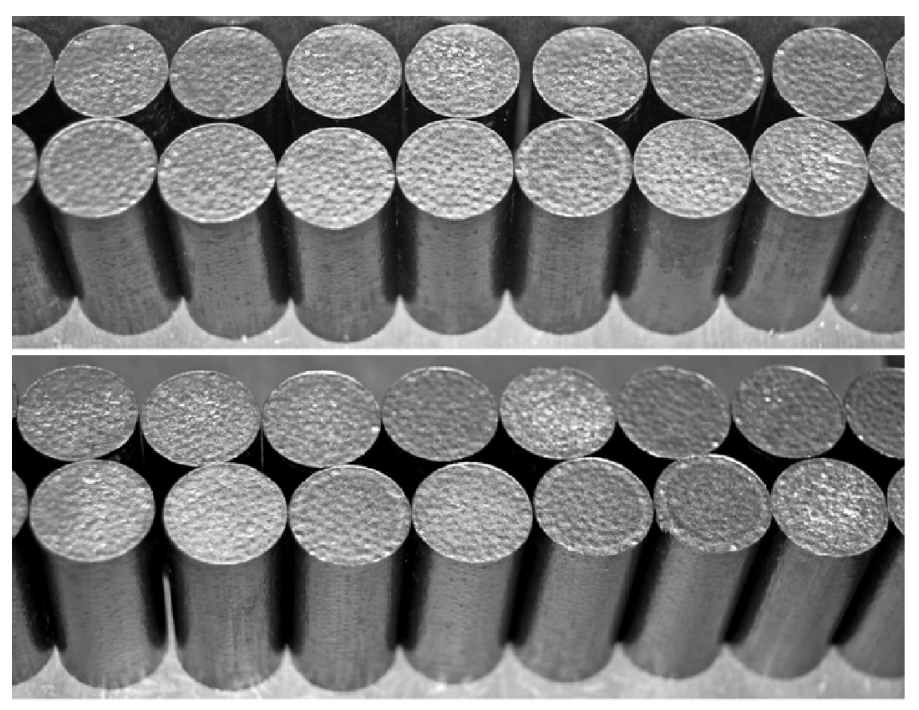

Figure 10. Photographs of heat-treated compacts pressed at $175^{\circ} \mathrm{C}$ for 50 seconds (top) and at $168^{\circ} \mathrm{C}$ for 93 seconds (bottom) produced during the time and temperature study at B\&W. 


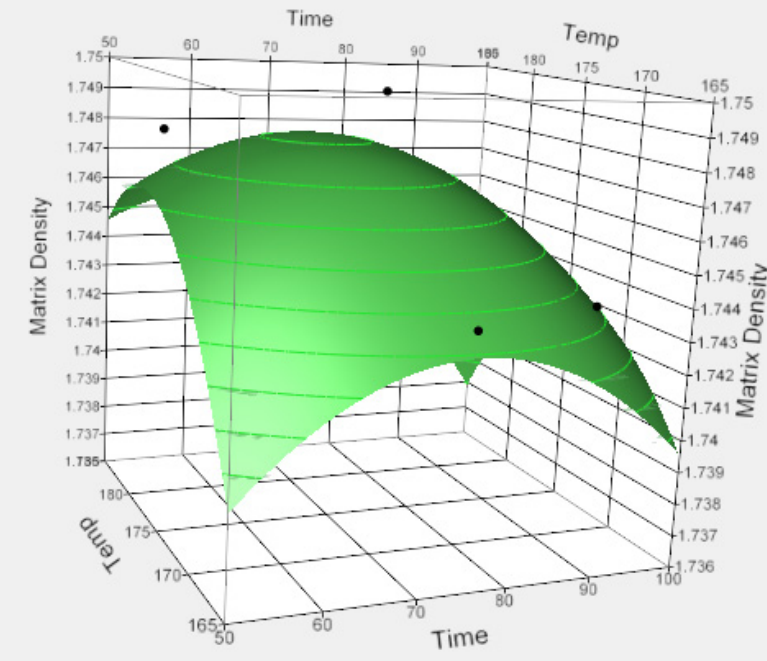

\begin{tabular}{|c|c|c|c|}
\hline Parameter & tRatio & \multicolumn{2}{|c|}{ Significance } \\
\hline Temperature 2 & -4.80 & & \multirow{3}{*}{$\begin{array}{l}1 \\
\vdots \\
\vdots \\
\vdots \\
\vdots\end{array}$} \\
\hline Time ${ }^{2}$ & -4.22 & & \\
\hline Time & -3.46 & & \\
\hline Temp & 2.15 & & \\
\hline Temp*Time & -1.98 & & , \\
\hline
\end{tabular}

Figure 11. Graph of compact matrix density analysis as a function of hot pressing temperature and hold time from the central composite design to determine optimal time and temperature set points for matrix density along with the relative significance of the variables and interactions.

\subsection{Low Pressure Factorial Experiment}

Pressure was determined to be insignificant over the range of pressures tested (16 to $20 \mathrm{MPa}$ ) for the factorial design at $46 \mathrm{Vol} \% \mathrm{PF}$. It is known, however, that there is a threshold value of pressure below which matrix density and packing fraction will begin to decrease. B\&W performed a follow-up compaction experiment using a single matrix (Hexion SD-1708 based) and repeated test conditions from the initial factorial design presented in Table 2, but with the single resin and at lower pressures. The modified design is shown in Table 6. Time at temperature was not factored in as one of the variables, but was thought to have an influence on the compact density and quality as a function of temperature.

B\&W pressed compacts using overcoated NUCO fuel at compacting temperatures of 145,160 , and $190^{\circ} \mathrm{C}$. Time was held at the same levels as that used in the previous factorial experiment. Compaction pressures were reduced to 10 and $14 \mathrm{MPa}$ in these trials, and compacts were measured, carbonized and heat treated, and re-measured to allow estimation of matrix density and packing fraction. Estimated matrix density and packing fraction data are shown in Table 7. Photographs on selected compacts are shown in Figure 9 (above) and Figure 12.

These results show that matrix density falls off to unacceptable levels at $10 \mathrm{MPa}$ but is still within the targeted density range of $1.75 \mathrm{~g} / \mathrm{cm}^{3}$ when pressed at the $14 \mathrm{MPa}$ pressure setting for a $46 \% \mathrm{PF}$. These data provide valuable information for the processing envelope for achieving compacts with matrix density in the acceptable level. 
Table 6. Test parameters for lower pressure study on matrix density and packing fraction.

\begin{tabular}{|c|c|c|c|c|c|}
\hline Lot & Resin & $\begin{array}{c}\text { Packing Fraction } \\
(\%)\end{array}$ & $\begin{array}{c}\text { Temperature } \\
\left({ }^{\circ} \mathrm{C}\right)\end{array}$ & $\begin{array}{c}\text { Hold Time } \\
(\text { seconds })\end{array}$ & $\begin{array}{c}\text { Pressure } \\
(\mathrm{MPa})\end{array}$ \\
\hline 13059 & Hexion SD-1708 & 46 & 190 & 40 & 14 \\
\hline 13060 & Hexion SD-1708 & 46 & 190 & 40 & 10 \\
\hline 13061 & Hexion SD-1708 & 46 & 160 & 90 & 14 \\
\hline 13062 & Hexion SD-1708 & 46 & 160 & 90 & 10 \\
\hline 13063 & Hexion SD-1708 & 46 & 145 & 220 & 14 \\
\hline 13064 & Hexion SD-1708 & 46 & 145 & 220 & 10 \\
\hline
\end{tabular}

Table 7. Results from lower pressure study.

\begin{tabular}{|c|c|c|c|c|}
\hline Lot & $\begin{array}{c}\text { Temperature } \\
\left({ }^{\circ} \mathrm{C}\right)\end{array}$ & $\begin{array}{c}\text { Hold Time } \\
(\text { seconds })\end{array}$ & $\begin{array}{c}\text { Est. Matrix } \\
\text { Density }\left(\mathrm{g} / \mathrm{cm}^{3}\right)\end{array}$ & $\begin{array}{c}\text { Est. Packing } \\
\text { Fraction }(\%)\end{array}$ \\
\hline 13059 & 190 & 40 & 1.72 & 47.5 \\
\hline 13060 & 190 & 40 & 1.68 & 46.9 \\
\hline 13061 & 160 & 90 & 1.73 & 47.6 \\
\hline 13062 & 160 & 90 & 1.67 & 46.8 \\
\hline 13063 & 145 & 220 & 1.72 & 47.5 \\
\hline 13064 & 145 & 220 & 1.67 & 46.7 \\
\hline
\end{tabular}

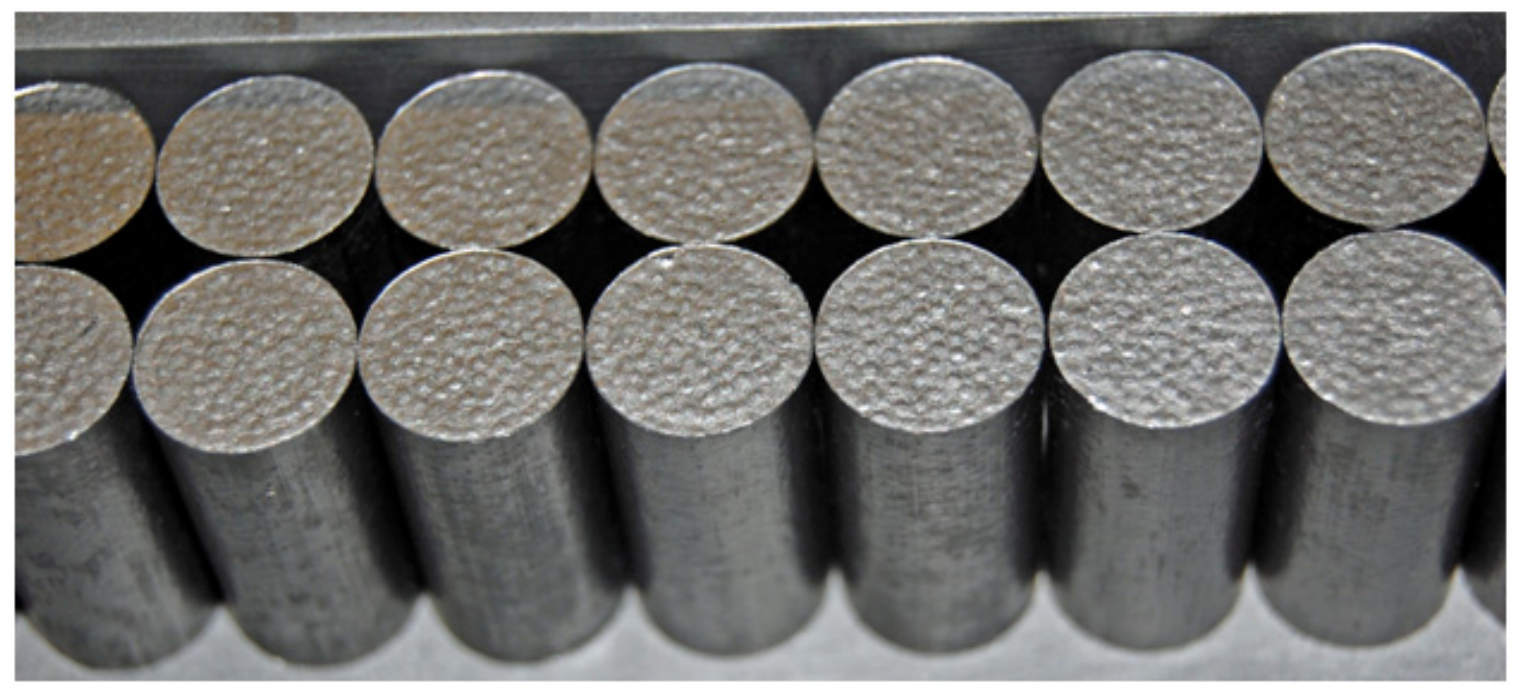

Figure 12. Photograph of heat treated compacts from lot 13063. 


\section{CERAMOGRAPHY RESULTS}

\subsection{General Matrix Structure}

As part of the characterization effort for compaction development, B\&W cross sectioned NUCO fuel compacts to evaluate the microstructure. Figure 13 shows the matrix where regions of high flow and low flow can be observed along with a fissure in the structure. The flow zoning and formation of fissures are thought to be the result of pressure applied before the matrix in the interior of the compact has achieved an adequate temperature $\left(\sim 130^{\circ} \mathrm{C}\right)$ for optimal flow. Oak Ridge National Laboratory (ORNL) was requested to analyze heating rates of overcoated NUCO in a die cavity at temperatures ranging from 145 to $190^{\circ} \mathrm{C}$ to determine the time required for overcoated fuel particles in the interior to heat to an adequate temperature prior to applying pressure.

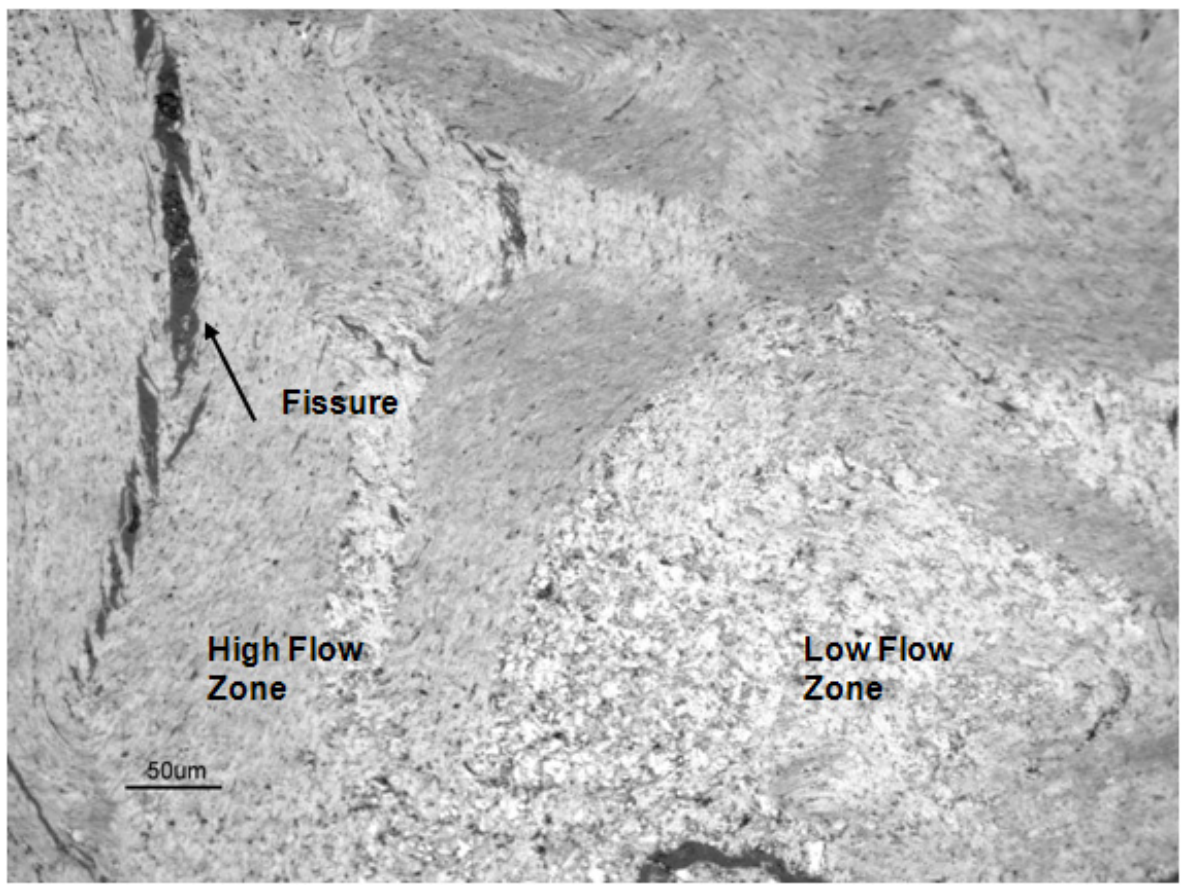

Figure 13. Photomicrograph showing matrix structure in a heat treated compact including regions of high and low flow along with an apparent fissure.

\subsection{Incidental Particle Contact}

Figure 14 shows fuel particles in the compact making contact with one another with four fuel particles touching. No apparent damage is visible in the TRISO layers on these fuel particles. Particle-toparticle contact is increasingly likely with higher packing fractions, and minimizing compaction pressure to achieve targeted matrix density will be increasingly important to minimize damage to the TRISO layers. Particles near the edge of the compacts were also evaluated as shown in Figure 15. None of these particles showed any damage to the outer pyrolytic carbon (OPyC) layers. Compacts do have some surface texture (refer to Figure 1 and Figure 9) because of matrix shrinkage during the heat treatment cycle. This texture could be lessened by reducing the percentage of resin in the matrix. 


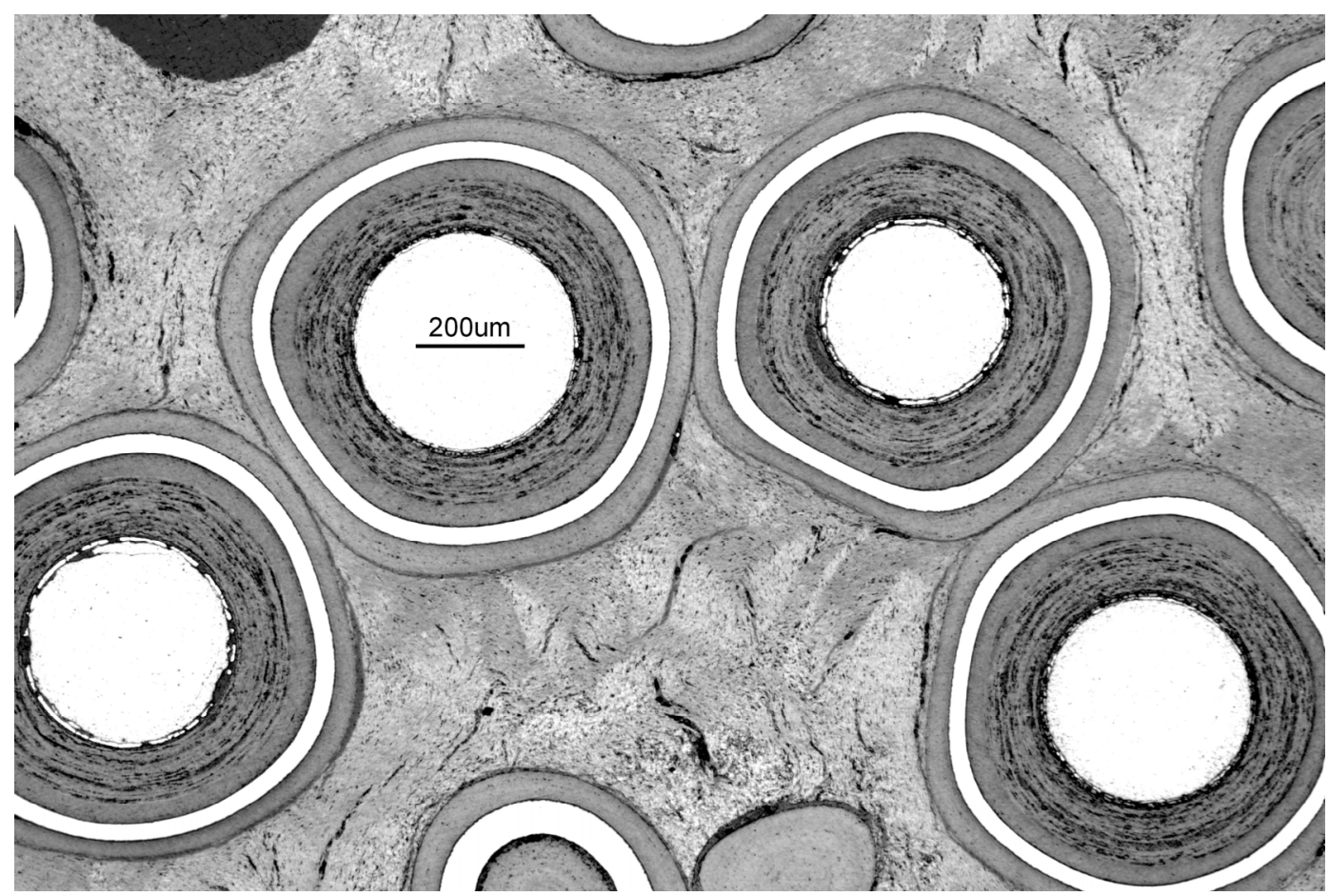

Figure 14. Photomicrograph from a NUCO fuel compact showing particle to particle contact in the compact but no particle or TRISO layer damage.
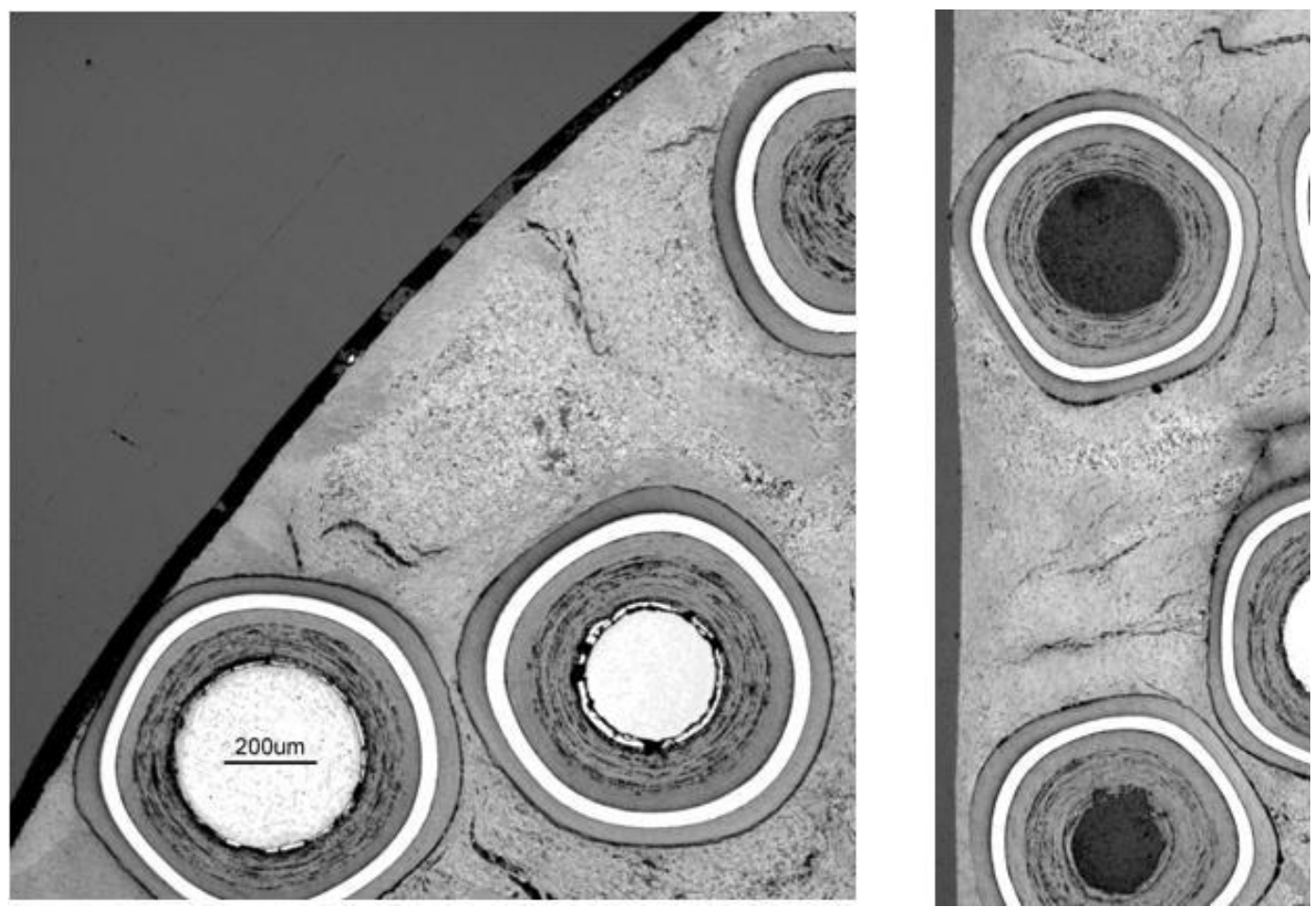

Figure 15. Photomicrograph showing NUCO particles near the surface along the radius (left) and length (right) of selected compacts. 


\subsection{Particle Damage}

Some fuel particles displayed some evidence of layer damage as shown in Figure 16 and Figure 17. Figure 16 shows particles removed from heat treated compacts by electrolytic deconsolidation and acid leaching. Partial removal of the OPyC layer was noted on several particles and a few particles showed damage to the silicon carbide $(\mathrm{SiC})$. The cracks in these particles, however, appear to have initiated in the fuel kernel and propagated through the buffer and inner pyrolytic carbon layers into the $\mathrm{SiC}$ layer, so it is not clear how the damage is occurring. The damage may be due to the sample preparation method. Figure 17 shows a NUCO fuel particle in a compact with a through-wall crack that extends from the fuel kernel through the $\mathrm{OPyC}$ layer. There is no evidence of the matrix material extruding into the crack, which would be one indication that the crack resulted from compaction, but compaction may still be the root cause for this crack. Additional information from burn-leach analysis was collected and analyzed with the intent to confirm the extent of particle damage due to the compaction process, but it was ultimately shown that the burn-leach test could not be used for this purpose.
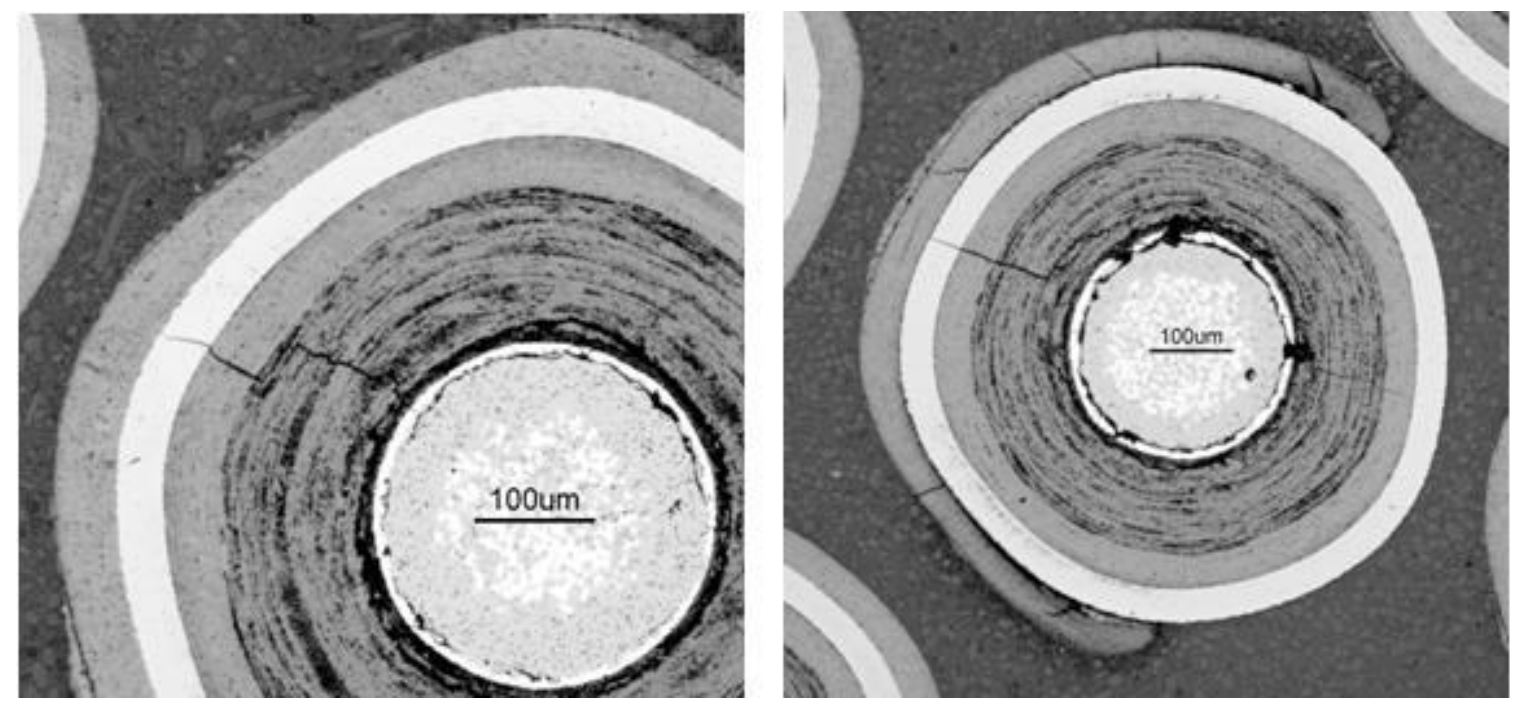

Figure 16. Photomicrograph of deconsolidated particles showing cracks propagating from the kernel into the SiC layers. 

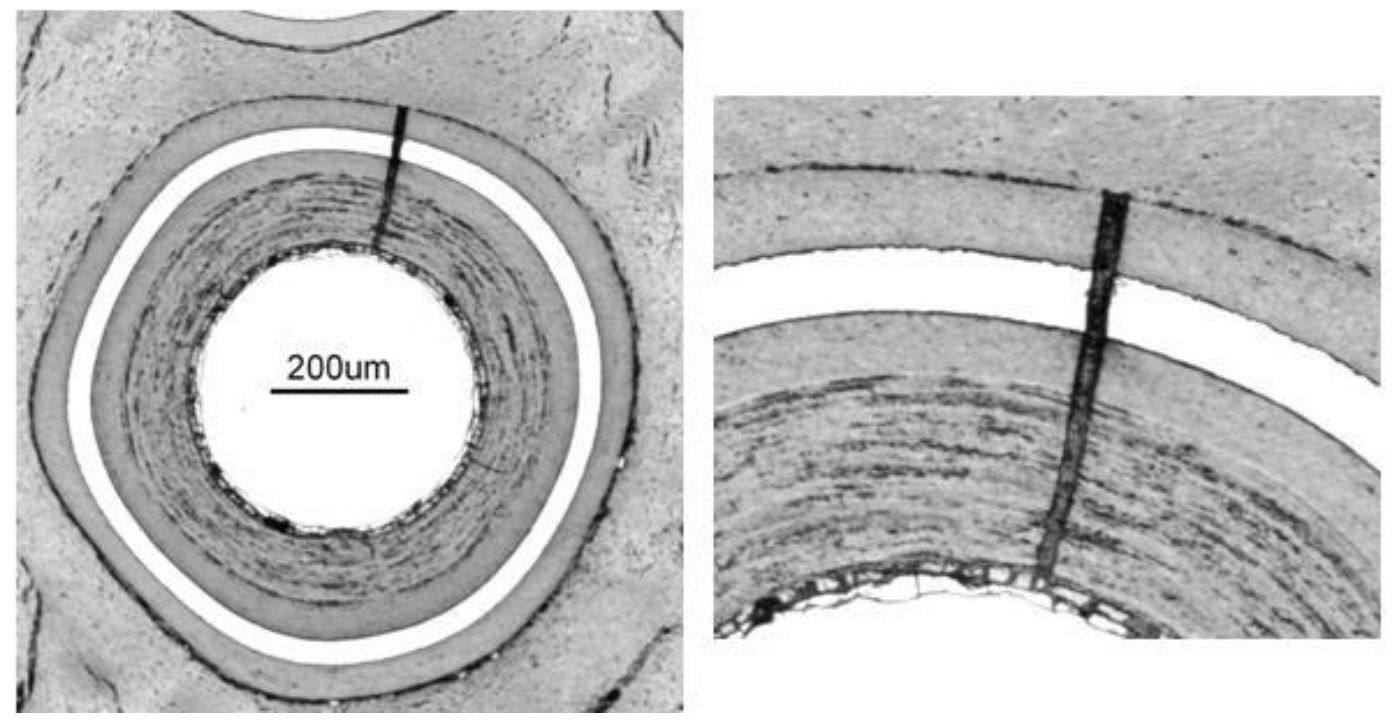

Figure 17. Photomicrograph of a NUCO particle in a compact showing a through-wall crack. Photo on the right is higher magnification of the same crack.

\subsection{Particle Damage Analysis}

It is expected that a definite relationship exists between packing fraction and allowable compacting pressure to prevent particle damage, and that a limiting packing fraction exists beyond which compacting without particle damage is not feasible using this process. A similar but secondary relationship is also expected between forming rate and allowable pressure at a given packing fraction.

Theoretical close packing of perfect spherical particles in an infinite array would allow a maximum packing fraction of $74 \mathrm{Vol} \%$. Edge effects from the compact side wall and ends in a cylindrical configuration, however, reduce this maximum to only $60 \%$. $^{\text {a }}$ At $35 \%$ packing fraction, only $58 \%$ of the available space in the compact is used. At $47 \%$ packing fraction, over $78 \%$ of the available space is required. At high packing fractions, the overcoating and compacting method forces individual particles to seek out a near close packing position within the compact during formation as shown in Figure 18. Such locations are not always available at high packing fraction because of the proximity of other particles and compact edges and ends. This situation is thought to result in multiple particle-to-particle contacts and localized high contact stresses between particles. Reduction of the compacting pressure reduces the maximum localized contact stress feasible. Decreasing the forming rate allows more time for the particles to adjust within the matrix to seek their lowest stress position. During original planning of the compacting scale-up effort, the ultimate feasibility of the overcoating and compacting method was estimated to be limited to about $40 \%$ packing fraction, which was more than desired at that time. An alternate process approach was recommended if very high packing fraction was required. ${ }^{3}$

Fuel particle damage analysis has been performed both with the ORNL deconsolidation and leach method and the compact burn leach method to determine the levels of exposed uranium content of fuel compacts. The deconsolidation method provides a benefit in that individual particles can be sectioned for evaluation, but the burn leach method was thought to be the most efficient method to accurately show levels of exposed uranium in a single test. It was later found that the burn leach method does not provide valid fuel particle damage results. Initial testing of 15 sets of five compacts each from different fuel tests have been analyzed (11 using the burn leach method). This data indicated that compacting at $47 \%$ 
packing fraction using high forming rates at pressures above $13 \mathrm{MPa}$ (1885 psi or $\sim 358 \mathrm{lbs}$ force on punch) consistently shows fuel particle damage. Earlier ORNL data indicated that at $37 \%$ packing fraction and low forming rates, the limiting pressure is $>22 \mathrm{MPa}(3,190 \mathrm{psi}$ or $\sim 606 \mathrm{lb}$ force on punch). Particle damage rates up to $2.0 \mathrm{E}-3$ have been observed at $47 \%$ packing fraction and pressures of $20 \mathrm{MPa}$ as shown in Table 8.

The data in Table 8 and plotted in Figure 19 seemed to indicate that reducing the forming pressure may reduce the extent of particle damage, but reduction sufficient to eliminate particle damage may take pressures of $9 \mathrm{MPa}$ or lower (1,300 psi or $\sim 250 \mathrm{lb}$ force), resulting in the matrix densities below desired levels. Further efforts are required to confirm the effect of lower forming pressures on high packing fraction compacts. One lot (13033) had an acceptable defect fraction and a second lot (13060) was marginally above the $2 \times 10^{-5}$ specification (from Advanced Gas Reactor [AGR] experiment AGR-2) for heavy metal contamination fraction. Lot 13033 had issues with the nitrogen springs during compaction such that the maximum pressure was $\sim 13 \mathrm{MPa}$, but the rate of pressure increase may have been significantly different because of a nitrogen spring pressure issue. The potential involvement of a change in application of forming pressure is one indication that forming rate may be a significant parameter in achieving compact formation at high packing fraction without particle breakage.

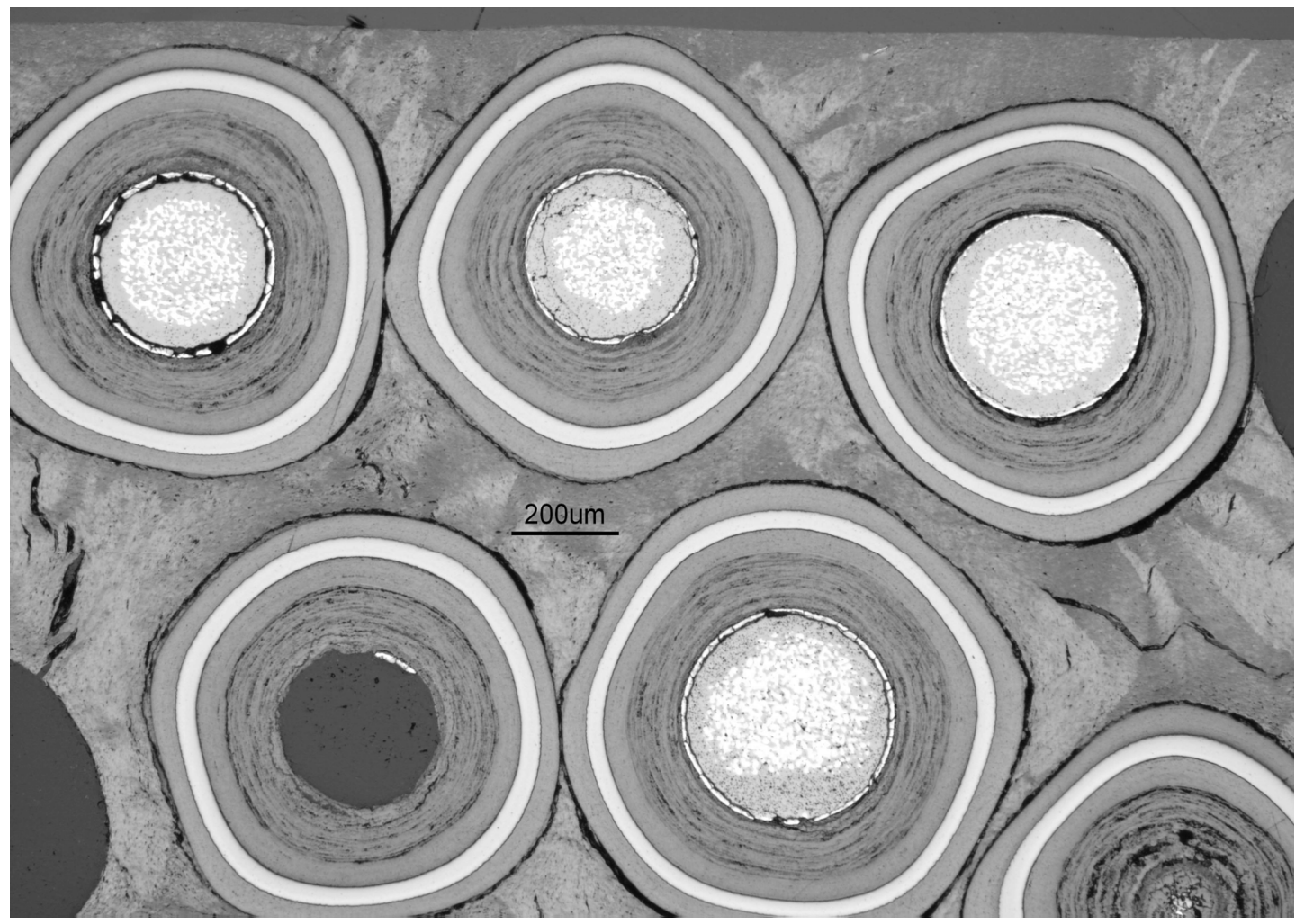

Figure 18. Longitudinal photomicrograph of 13041 showing near close pack loading of fuel particles. 


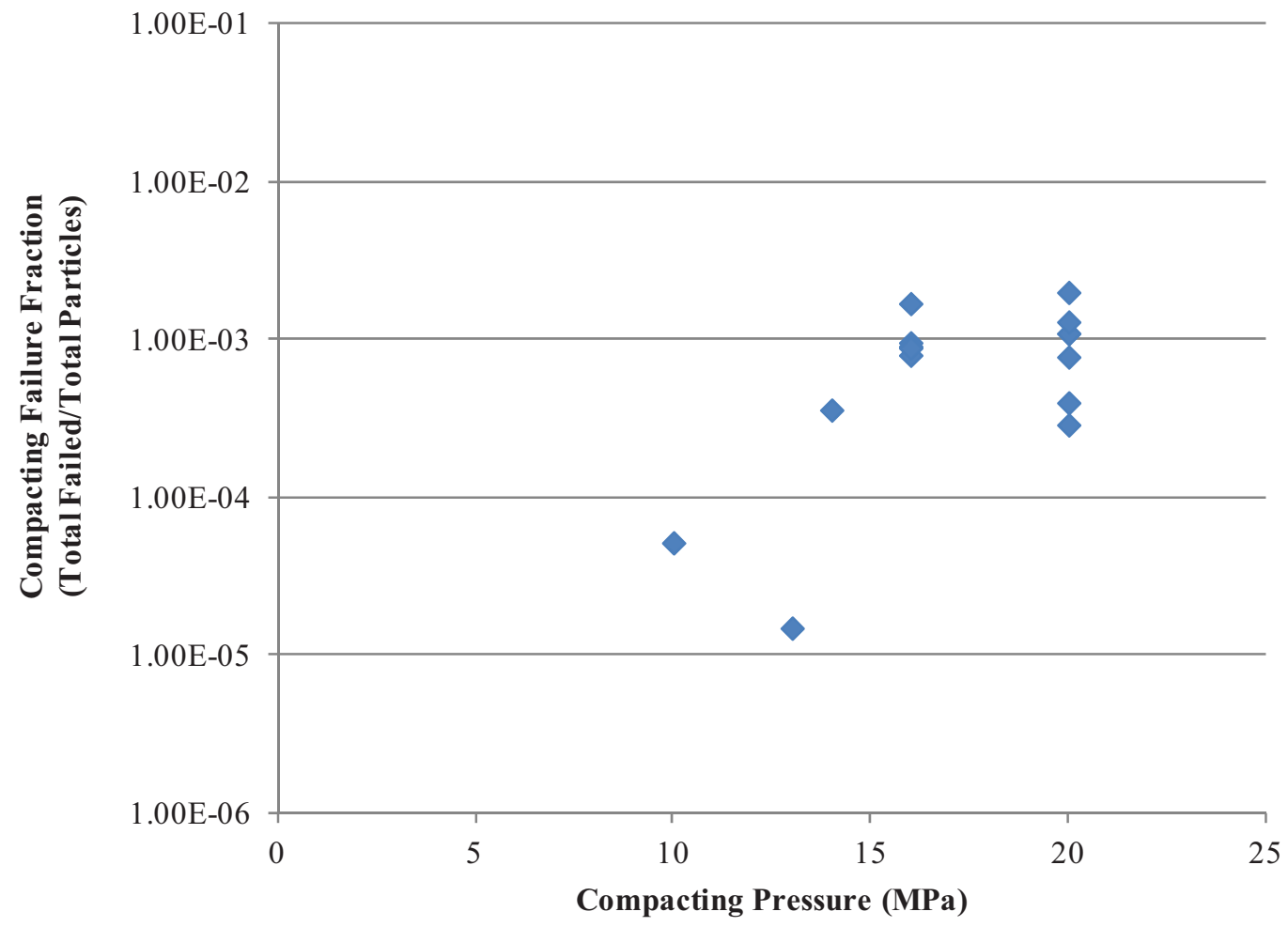

Figure 19. Graph of defect fraction as a function of forming pressure from compact lots pressed from $46 \%$ packing fraction overcoated NUCO lots listed in Table 8. 


\section{FINAL NUCO HOT PRESSING TRIALS-PACKING FRACTION AND PRESSURE STUDY}

Because of the damage associated with the previous testing, a new phase of testing was conducted to determine if damage was due to high packing fraction, high forming pressure or some other unknown cause. Prior to completing these test, INL and B\&W evaluated green compacts for damage to confirm that thermal treatment was not inducing defects due to thermal stress on the compacts. Green compacts (no thermal heat treatment) were pressed and analyzed for broken particles. The results from this testing determined that the levels of broken particles were comparable to compacts after heat treatment. This suggests that damage is primarily occurring during either the overcoating or compaction processes.

INL and $\mathrm{B} \& \mathrm{~W}$ also confirmed that pressing rate was more rapid than intended. It was determined that the main ram was descending at a rate of $200 \mathrm{~mm} / \mathrm{second}$ and not slowing to a slower rate (40 $\mathrm{mm} / \mathrm{second}$ ) on the first indication of pressure. The ram was actually shifting rates based on ram position and it was found that the shift position was after most if not all of the actual compact formation had occurred at the high pressing rate. It was suspected that this was the source for particle damage.

Adjustments were made to slow the pressing rate to $5 \mathrm{~mm} / \mathrm{second}$ and adjusting the press position to shift to the lower rate well before significant compact pressurization occurred to ensure that the press rate would be at the slower rate during compact formation. Sixteen 16 compacts were pressed at $145^{\circ} \mathrm{C}$ and $20 \mathrm{MPa}$ pressure, and compacts were submitted for broken particle analysis in the green state. The results from these compacts also indicated comparable particle damage levels. It is suspected that any advantages of the slower rate were offset by the higher forming pressure and have confirmed that $20 \mathrm{MPa}$ of forming pressure is excessive for a $46 \%$ packing fraction system.

For the packing fraction and pressure study, a $3 \times 3$ factorial test matrix was employed to evaluate three packing fractions $(35,41$, and $46 \%)$ and three forming pressures $(7,11$, and $15 \mathrm{MPa})$. The test matrix is shown in Table 9. Samples of NUCO were also collected after the overcoating operation and again after discharge from the slide gate on the material hopper to verify that damage was not being induced at these stages of the process. Approximately $50 \mathrm{~g}$ were sampled for this analysis. Particle damage results on the NUCO after overcoating as well as the overcoated material fed from the hopper to the die cavity as shown in Table 10 indicate that NUCO kernel defect levels are comparable to the base NUCO. Larger sampling would be required to provide confirmatory evidence, but these data suggest that the particle damage is resulting from the compaction process and not in the preceding processes.

Table 9. Factorial design used for packing fraction and pressure evaluation on NUCO fuel.

\begin{tabular}{|c|c|c|c|c|c|c|c|}
\hline Lot & $\begin{array}{c}\text { Temperature } \\
\left({ }^{\circ} \mathrm{C}\right)\end{array}$ & $\begin{array}{c}\text { Hold Time } \\
(\text { seconds })\end{array}$ & $\begin{array}{c}\text { Packing } \\
\text { Fraction } \\
(\%)\end{array}$ & $\begin{array}{c}\text { Pressure } \\
(\mathrm{MPa})\end{array}$ & $\begin{array}{c}\text { Est. Matrix } \\
\text { Density } \\
\left(\mathrm{g} / \mathrm{cm}^{3}\right)\end{array}$ & $\begin{array}{c}\text { Est. Packing } \\
\text { Fraction } \\
(\%)\end{array}$ & $\begin{array}{c}\text { Est. Particles } \\
\text { per Compact }\end{array}$ \\
\hline 13070 & 177 & 68 & 35 & 7 & 1.68 & 34.0 & 3087 \\
\hline 13071 & 177 & 68 & 41 & 7 & 1.66 & 39.7 & 3600 \\
\hline 13072 & 177 & 68 & 46 & 7 & 1.60 & 45.2 & 4586 \\
\hline 13073 & 177 & 68 & 35 & 11 & 1.78 & 35.2 & 3086 \\
\hline 13074 & 177 & 68 & 41 & 11 & 1.75 & 40.9 & 3604 \\
\hline 13075 & 177 & 68 & 46 & 11 & 1.71 & 46.6 & 4584 \\
\hline 13076 & 177 & 68 & 35 & 15 & 1.80 & 35.6 & 3081 \\
\hline 13077 & 177 & 68 & 41 & 15 & 1.78 & 41.4 & 3597 \\
\hline 13078 & 177 & 68 & 46 & 15 & 1.75 & 47.2 & 4581 \\
\hline
\end{tabular}


Table 10. Failed particle results on overcoated NUCO and overcoated NUCO discharged from the hopper.

\begin{tabular}{|c|l|c|c|c|}
\hline Batch & \multicolumn{1}{|c|}{ Location } & $\begin{array}{c}\text { Number of Particles } \\
\text { Sampled }\end{array}$ & Defective Particles & Defect Fraction \\
\hline 11010 & Blend & 28,811 & 2.40 & $8.33 \mathrm{E}-05$ \\
\hline 11010 & Overcoating & 28,811 & 2.17 & $7.53 \mathrm{E}-05$ \\
\hline 11010 & Hopper & 28,811 & 3.43 & $1.19 \mathrm{E}-04$ \\
\hline 11012 & Blend & 22,976 & 0.82 & $3.57 \mathrm{E}-05$ \\
\hline 11012 & Overcoating & 22,976 & 0.00 & $0.00 \mathrm{E}+00$ \\
\hline 11012 & Hopper & 22,976 & 0.00 & $0.00 \mathrm{E}+00$ \\
\hline 11013 & Blend & 24,306 & 0.86 & $3.54 \mathrm{E}-05$ \\
\hline 11013 & Overcoating & 24,306 & 0.00 & $0.00 \mathrm{E}+00$ \\
\hline 11013 & Hopper & 24,306 & 1.05 & $4.32 \mathrm{E}-05$ \\
\hline 11014 & Blend & 26,198 & 0.94 & $3.59 \mathrm{E}-05$ \\
\hline 11014 & Overcoating & 26,198 & 1.70 & $6.49 \mathrm{E}-05$ \\
\hline 11014 & Hopper & 26,198 & 1.35 & $5.15 \mathrm{E}-05$ \\
\hline
\end{tabular}

NUCO for this factorial experiment was overcoated with matrix targeting packing fractions of 35 and $41 \%$ based on the weight ratio of the matrix and NUCO. There was an adequate stock of $46 \%$ packing fraction overcoated NUCO from prior testing to complete these tests. Thirty-two compacts were pressed at each condition listed in Table 9 and dimensional data (weight, length, and diameter) measured on each. The pressing conditions are near the optimal level for highest matrix density per Figure 11 (above). Compacts were carbonized to $850^{\circ} \mathrm{C}$ under a partial vacuum with flowing nitrogen $\left(\mathrm{N}_{2}\right)$ to remove volatile gases and heat treated to $1800^{\circ} \mathrm{C}$ under vacuum. All compacts were re-measured to calculate weight and dimensional changes associated with the heat treatment. Five compacts from each condition were randomly selected and submitted for burn leach analysis.

From the results listed in Table 9 and graphed in Figure 20, there is an apparent effect between packing fraction and matrix density. As the packing fraction decreases, higher matrix density values (some which exceed the targeted level of $1.75 \mathrm{~g} / \mathrm{cm}^{3}$ ) are achieved at each pressure with differences more pronounced at the lower pressures. Not surprisingly, packing fraction also increases with increasing pressure. The use of the hot press process allows for matrix density values in excess of $1.60 \mathrm{~g} / \mathrm{cm}^{3}$ to be achieved at pressures as low as $7 \mathrm{MPa}$, even for a $46 \%$ packing fraction case.

Axial shrinkage and mass loss as a function of forming pressure are shown in Figure 21 and Figure 22. An interesting observation is a shift in the axial dimension from shrinkage to growth with increasing pressure and packing fraction. Compacts from 35 and $41 \%$ packing fraction NUCO pressed at $7 \mathrm{MPa}$ experienced axial shrinkage during carbonization and heat treatment; the remaining samples had axial growth and the $35 \%$ packing fraction pressed at $15 \mathrm{MPa}$ forming pressure had the highest axial growth of any set of compacts. The $35 \%$ compacts would have the greatest percentage of matrix and a higher aspressed matrix density. These compacts presumably would also have a higher percentage of gaseous products produced during carbonization and heat treatment. 


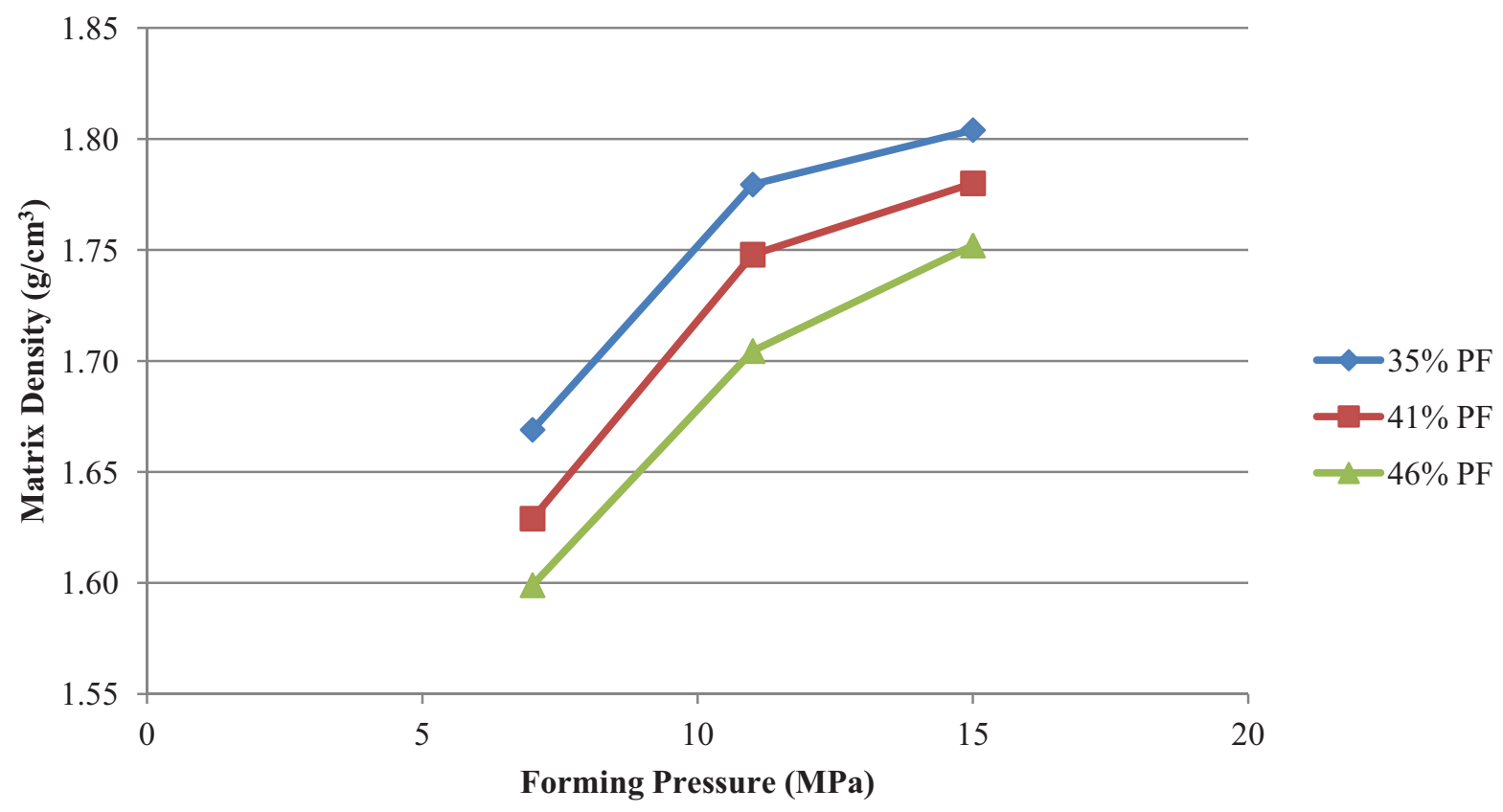

Figure 20. Graph of estimated compact matrix density as a function of forming pressure for the three different packing fraction cases.

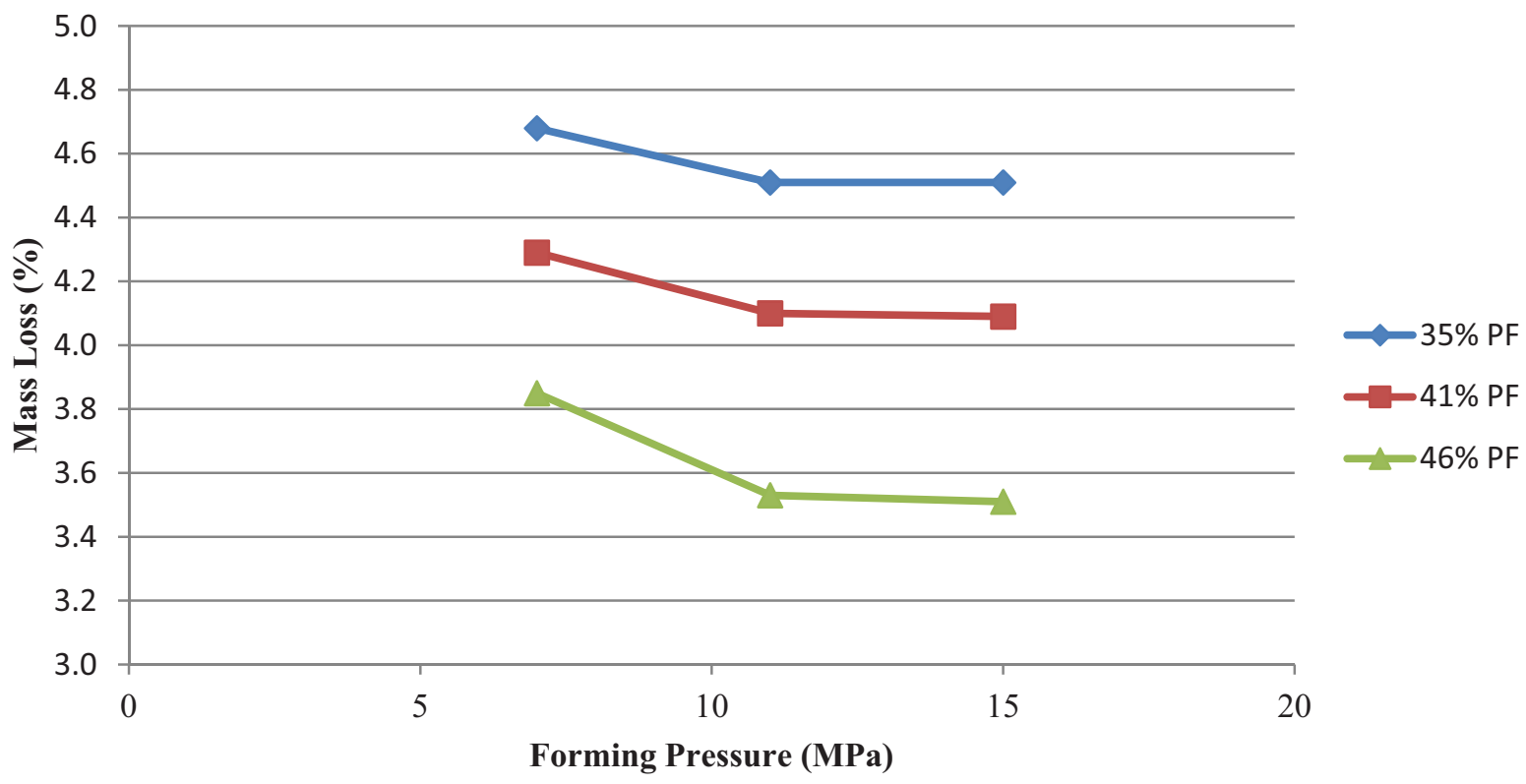

Figure 21. Graph of compact heat treated mass loss as a function of forming pressure. 


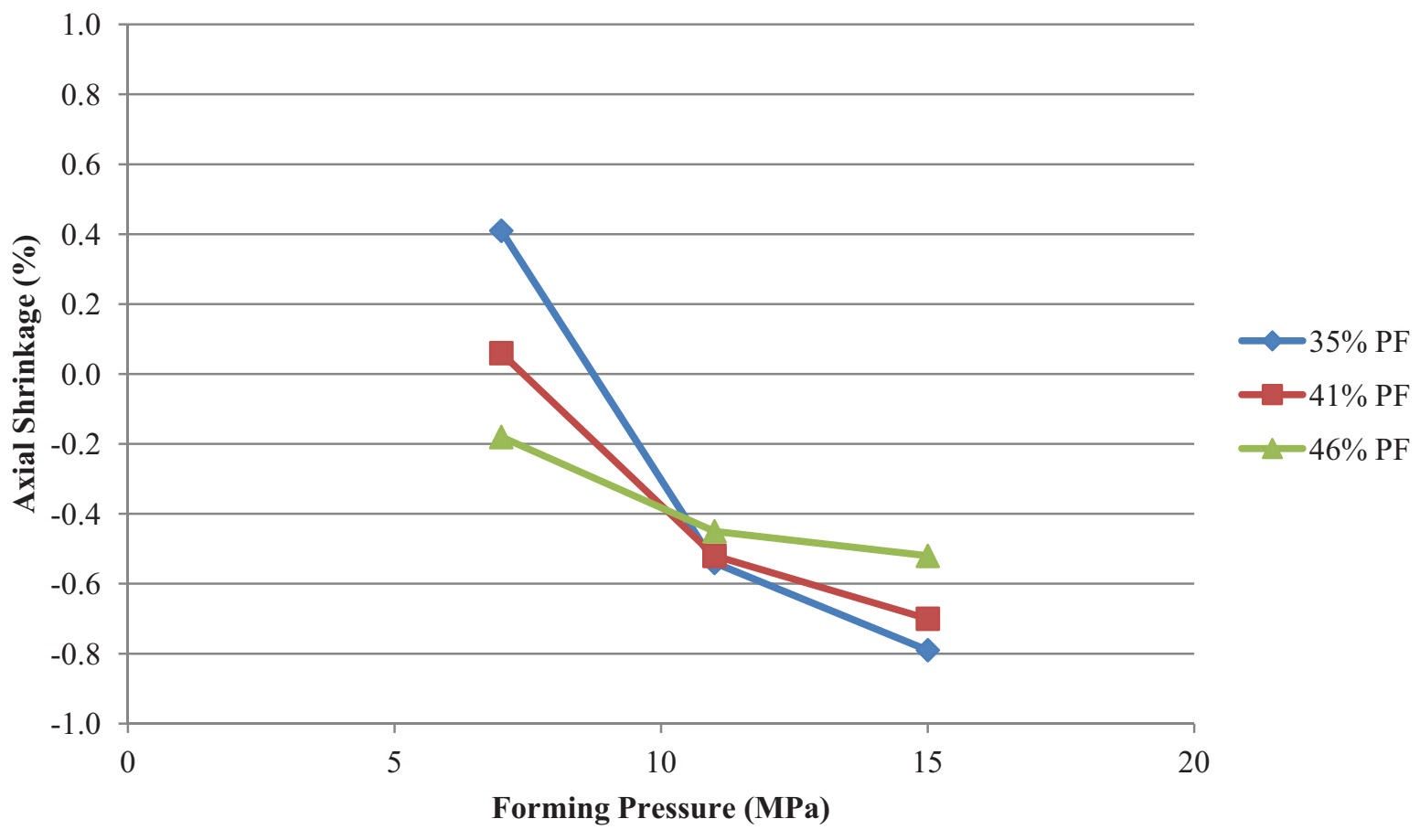

Figure 22. Graph of compact axial shrinkage as a function of forming pressure.

Mass loss, shown in Figure 21, should remain constant as a function of forming pressure for compacts pressed at a constant time and temperature. The data, however, show a decrease of approximately $0.2 \%$ for each overcoated condition from 7 to $11 \mathrm{MPa}$ and the weight loss remained relatively constant between 11 and $15 \mathrm{MPa}$ for the 35 and $41 \%$ materials and a decrease of approximately $0.35 \%$ for the $46 \%$ overcoated material. One possible explanation for these effects is that the lower pressures provide for a lower green density and more permeable structure which allows for gases evolved during forming and the carbonization process to escape from the compact. The premise was that the higher forming temperature coupled with the higher pressures may tend to restrict the rate at which some of the gaseous products can escape. If true, excess heating rates would promote formation of fissure cracks within the matrix during carbonization. ORNL performed thermogravimetric analysis (TGA) on matrix only compacts (Figure 23) to provide the data to allow optimization of the compaction process. Analyses showed that all potential gaseous products will escape the cured matrix, given sufficient diffusion time. Review of phenolic curing and post curing behavior showed that the resin post cure bakeout achieved at the start of carbonization may be the primary source of dimensional behavior variation in compacting.

Photos from selected heat treated compacts are shown in Figure 24. There are minor differences noted in the surface texture from compacts pressed from NUCO targeting the three packing fractions. These differences primarily result from fewer particles being at the surface with reduced packing fraction compacts and the additional overcoating thickness being applied to these fuel particles. Compacts pressed from the higher targeted packing fraction overcoated NUCO have a reduced thickness of overcoating and considerably higher number of particles per compact. This can be seen in Figure 24 as higher packing fraction compacts have more particles at the surface. Increasing the packing fraction from 35 to $46 \%$ increases the estimated number of particles per compact by approximately 1,500 particles (see Table 10). 


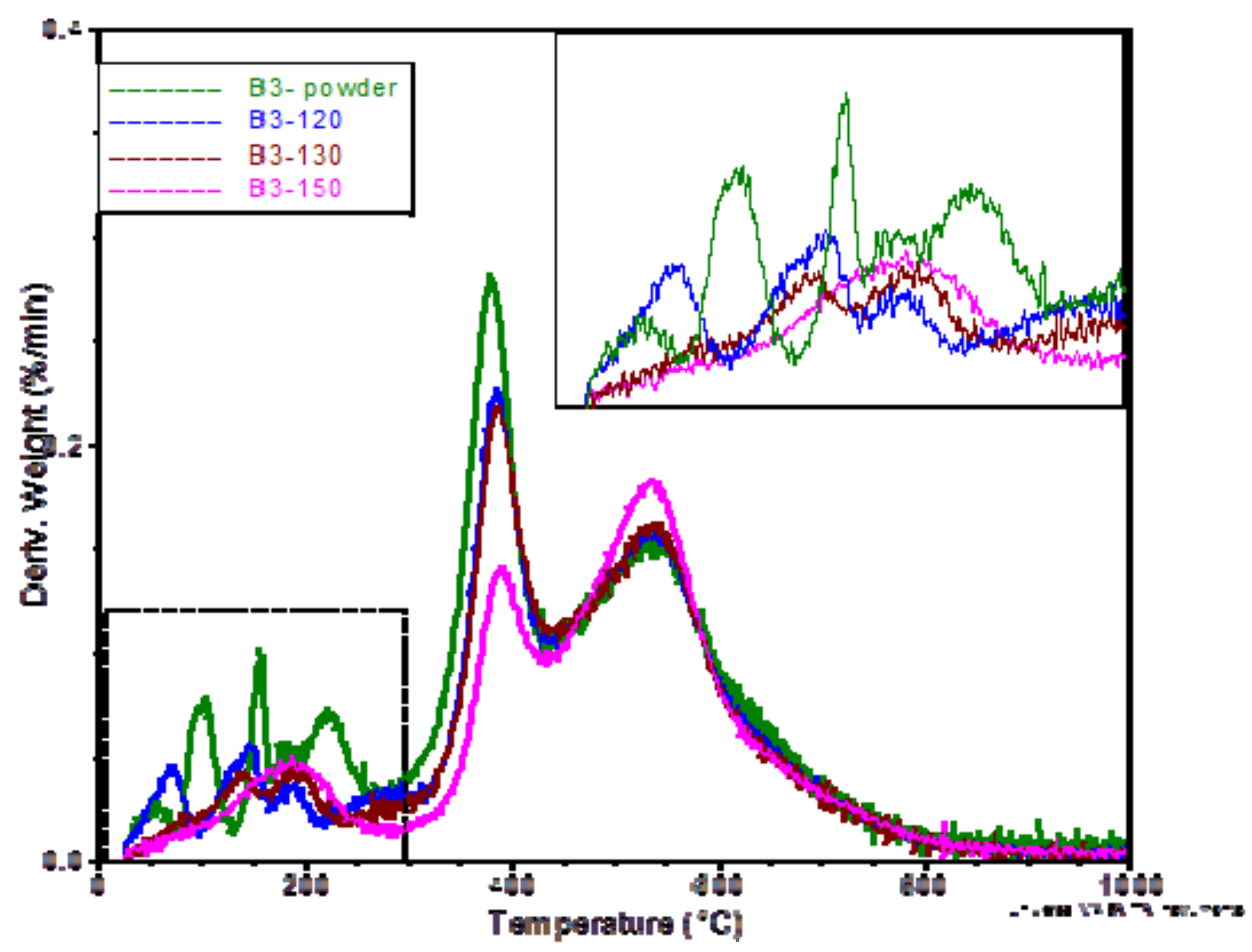

Figure 23. TGA analysis of 5\% HEXA resin matrix during carbonization. 

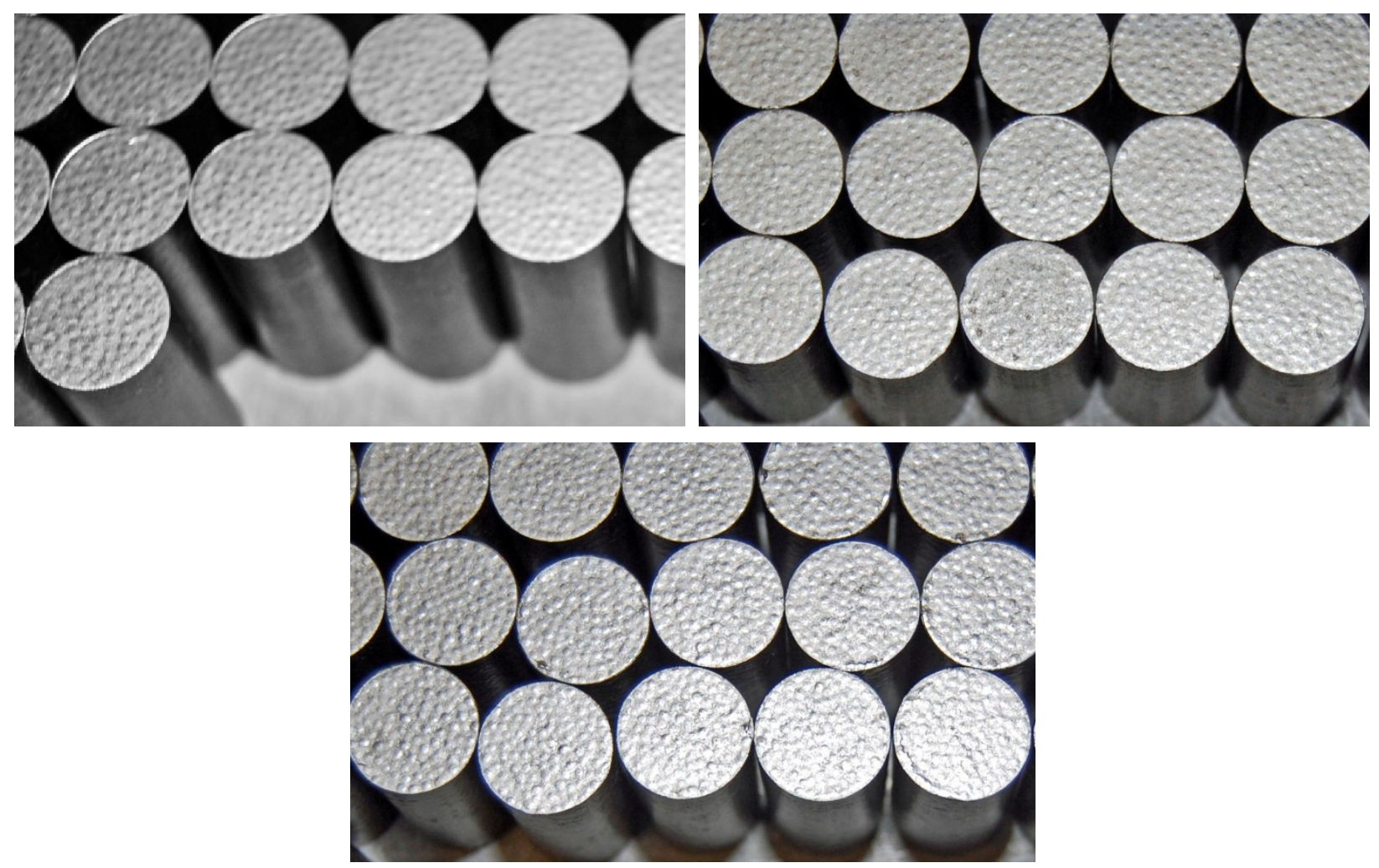

Figure 24. Photographs showing heat treated compacts pressed from targeted $35 \%$ (top), $41 \%$ (center), and $46 \%$ (bottom) packing fraction fuel at $15 \mathrm{MPa}$.

\subsection{Matrix Density Review}

The analysis of matrix density confirms that both matrix density and packing fraction (PF) are significant at a $95 \%$ confidence level. From the data obtained, matrix density can be estimated using the equation

$$
\begin{aligned}
\text { Matrix Density } & =1.83222+0.01726(\text { pressure })-0.00673(P F) \\
& +0.00068[(\text { pressure }-11) \times(P F-40.6692)]-0.00199(\text { pressure }-11)^{2} \\
& -0.00017(P F-40.6692)^{2}
\end{aligned}
$$

These results are shown graphically in Figure 25 where the region encased by the blue rectangle denotes the estimated matrix density specification of 1.67 to $1.83 \mathrm{gm} / \mathrm{cm}^{3}$ targeted for AGR-5/6/7; lines represent theoretical calculations while actual data are shown as points. From these results, it is apparent that lowering the packing fraction allows for a higher matrix density to be achieved at lower forming pressures. Increasing the packing fraction requires higher forming pressures to achieve comparable matrix density values as shown in Figure 26 and Figure 27. For packing fraction conditions of 35 to $38 \%$, pressures as low as $7 \mathrm{MPa}$ (and even lower) yield compacts that have a matrix density within the targeted level and increasing the forming pressure to $\sim 9 \mathrm{MPa}$ is sufficient to achieve the nominal value of 1.75 $\mathrm{g} / \mathrm{cm}^{3}$. For a packing fraction condition of $47 \%$, forming pressures of $10 \mathrm{MPa}$ yield compacts at the lower region of the targeted specification, but pressures of 14 to $15 \mathrm{MPa}$ are necessary to achieve the nominal targeted value. Lowering the forming pressure reduces the likelihood for breaking TRISO particles during the compaction process, as does lowering the number of particles per compact. 


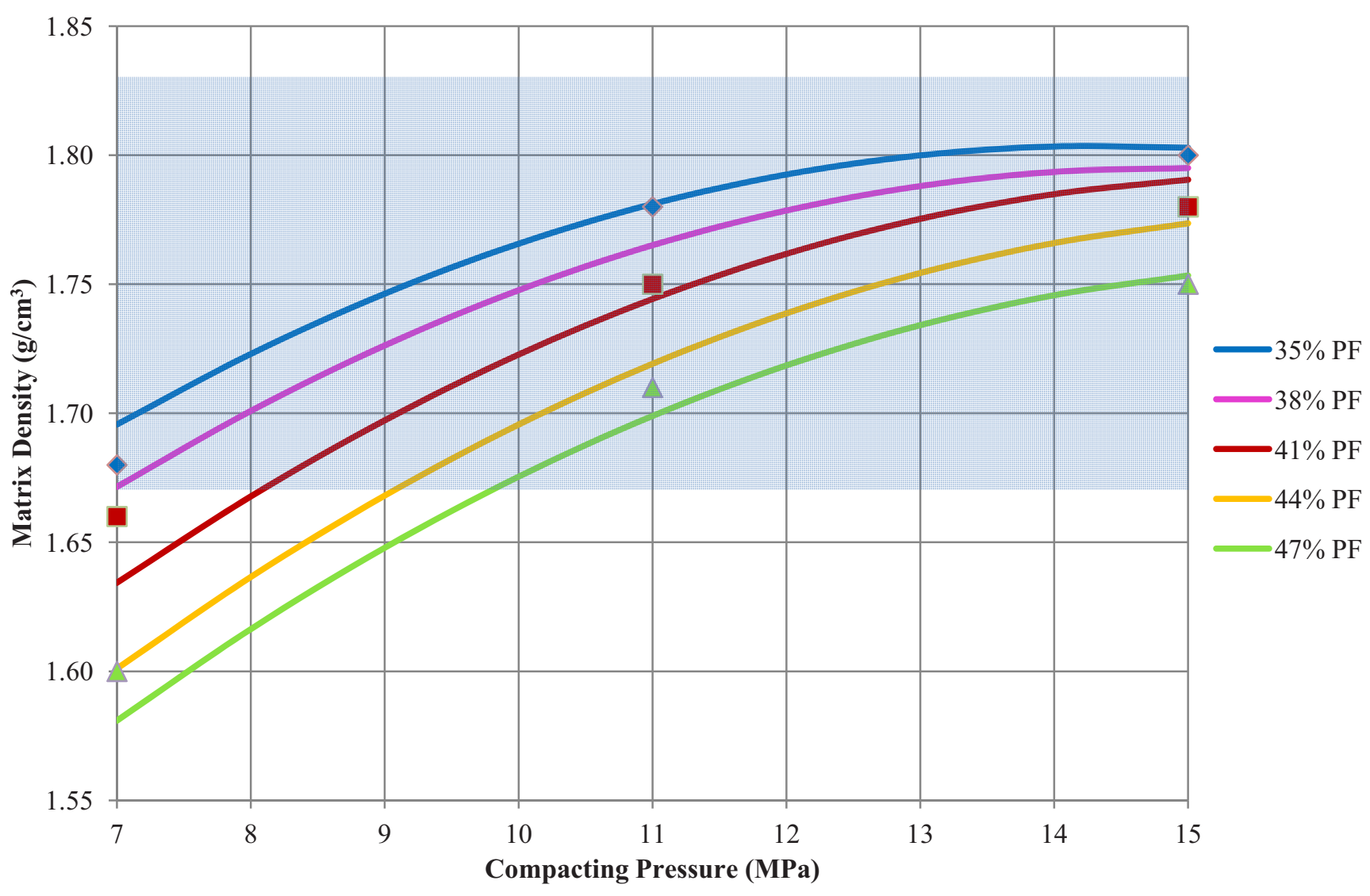

Figure 25. Graph of calculated matrix density as a function of forming pressure for various calculated packing fractions of overcoated NUCO. Points $(\diamond, n, \triangle)$ represent actual data from $35 \%, 41 \%$, and $46 \%$ packing fraction cases shown in Table 9 and graphed in Figure 20. 

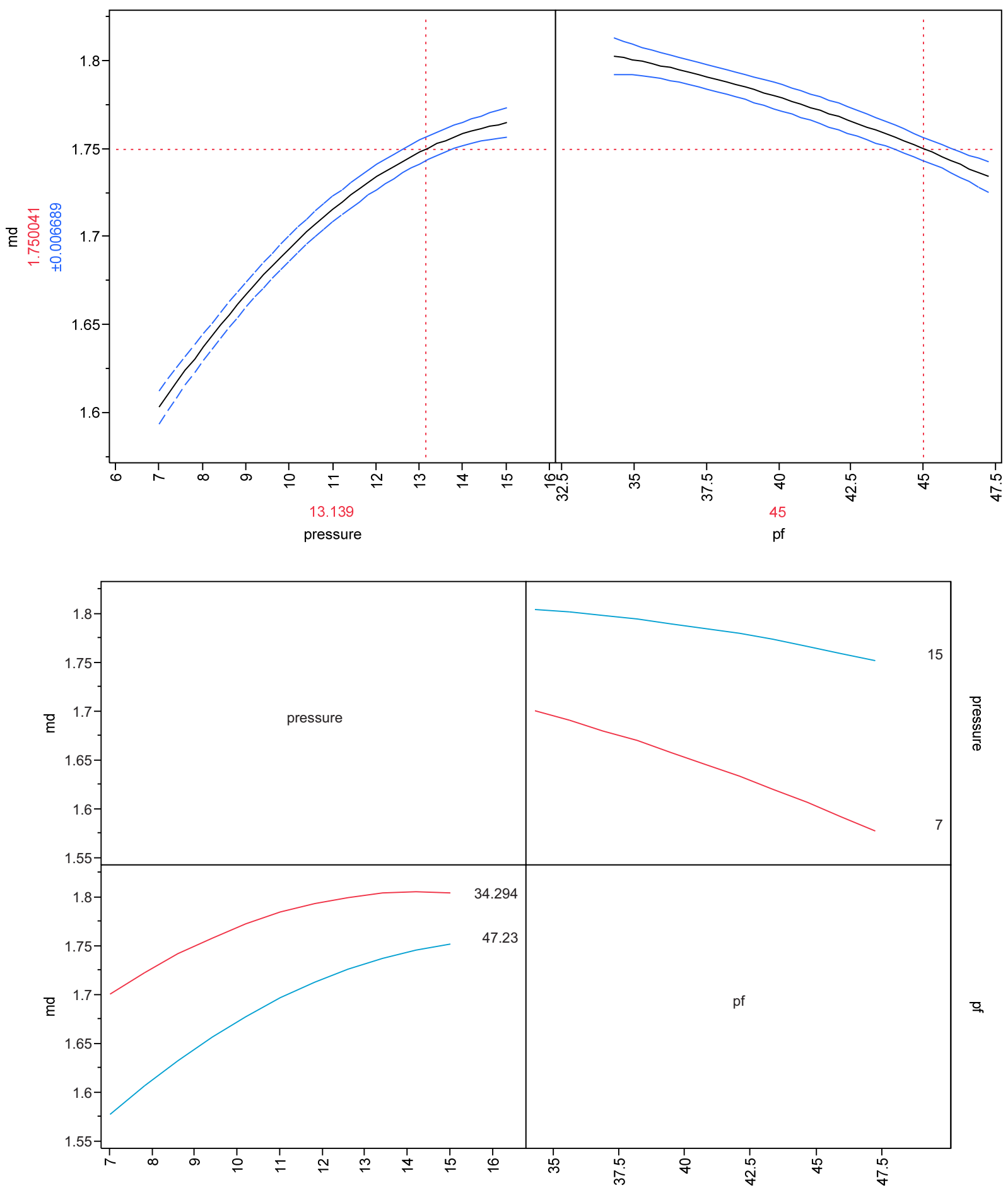

Figure 26. Plots showing the significance of forming pressure and packing fraction on matrix density. 


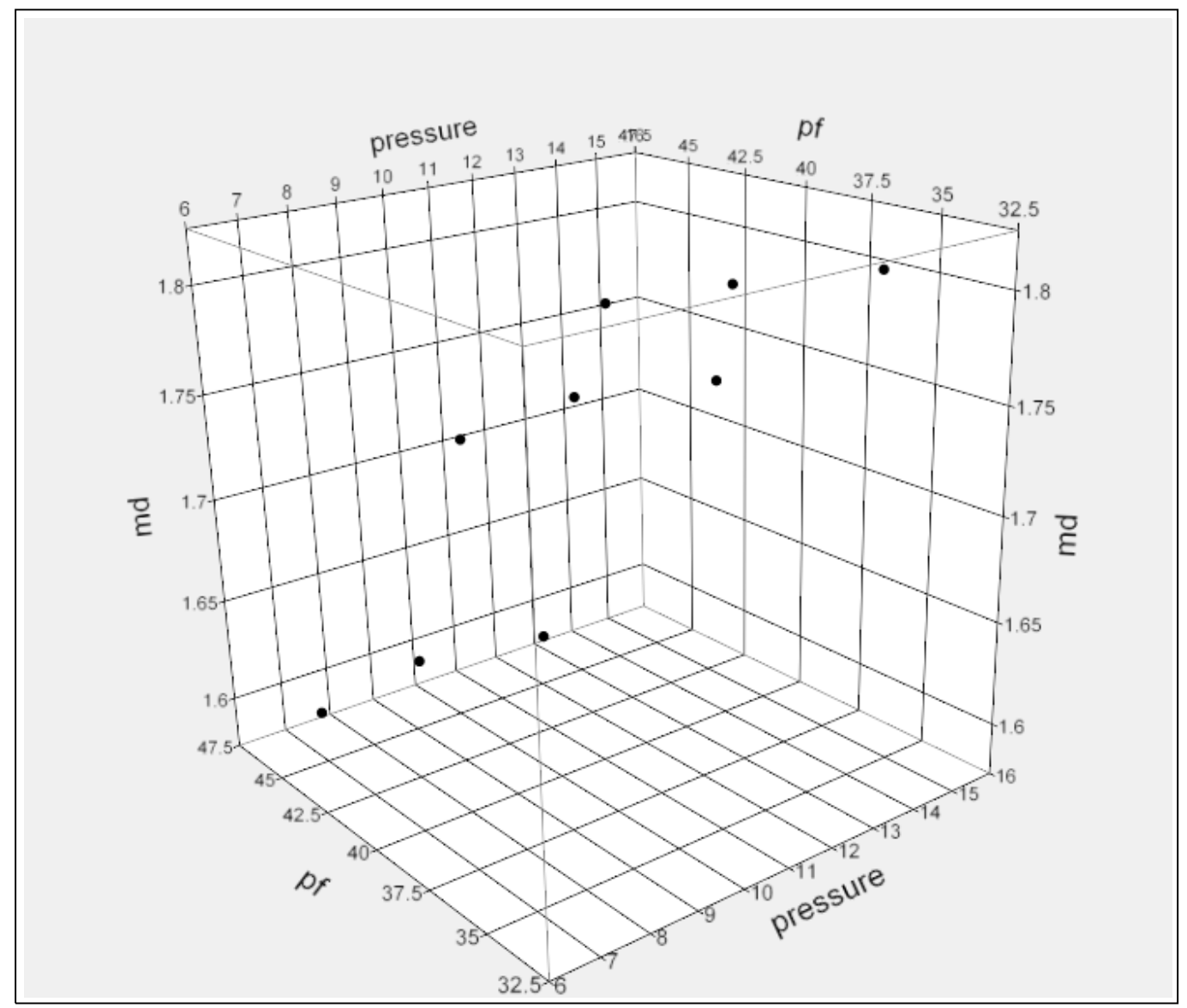

Figure 27. Graph showing matrix density as a function of packing fraction and forming pressure.

\subsection{Broken Particle Review}

Five compacts from each of the 9 test conditions were analyzed to measure the number of broken particles in each condition. Compacts were randomly selected and burn leach tested with the leachate solution analyzed for uranium to determine the quantity of uranium leached from the broken or damaged particles in each set (It was later learned that the burn leach test does not provide valid results). The burn back temperature was $900^{\circ} \mathrm{C}$ in a 15 hour cycle. Results from the testing are shown in Table 11. The compacting failure fraction listed in Table 11 is the difference between the total defect fraction and the failure fraction in the NUCO lot; the base failure rate associated with the base NUCO has been subtracted from the total defect fraction to arrive at this number.

The analysis of the results indicate that all test conditions had higher than acceptable failure rates for broken particles. The results are shown in Table 11 and graphed in Figure 28 which shows defect fraction as a function of forming pressure. This data contradicted previous results (Figure 19) which predicted that reducing forming pressure would lower failure rates. This discrepancy and the spike in failure fraction associated with the $35 \%$ packing fraction case at $7 \mathrm{MPa}$ and $41 \%$ packing fraction at $11 \mathrm{MPa}$ materials shown in Table 11 and Figure 27 led to discussions about potential root cause mechanisms. 
Table 11. Damaged particle results from packing fraction/forming pressure testing.

\begin{tabular}{|c|c|c|c|c|c|c|}
\hline Lot & $\begin{array}{c}\text { Est. Number } \\
\text { of Particles }\end{array}$ & $\begin{array}{c}\text { Defective } \\
\text { Particles }\end{array}$ & $\begin{array}{c}\text { Defective } \\
\text { Particles per } \\
\text { Compact }\end{array}$ & $\begin{array}{c}\text { Total Defect } \\
\text { Fraction }\end{array}$ & $\begin{array}{c}\text { NUCO Lot } \\
\text { Failure } \\
\text { Fraction }\end{array}$ & $\begin{array}{c}\text { Compacting } \\
\text { Failure } \\
\text { Fraction }\end{array}$ \\
\hline 13070 & 15,435 & 17.4 & 3.48 & $1.13 \mathrm{E}-03$ & $3.57 \mathrm{E}-05$ & $1.09 \mathrm{E}-03$ \\
\hline 13071 & 18,000 & 38.5 & 7.7 & $2.14 \mathrm{E}-03$ & $3.57 \mathrm{E}-05$ & $2.10 \mathrm{E}-03$ \\
\hline 13072 & 22,930 & 60.2 & 12.04 & $2.63 \mathrm{E}-03$ & $8.33 \mathrm{E}-05$ & $2.54 \mathrm{E}-03$ \\
\hline 13073 & 15,430 & 17.9 & 3.58 & $1.16 \mathrm{E}-03$ & $3.57 \mathrm{E}-05$ & $1.12 \mathrm{E}-03$ \\
\hline 13074 & 18,020 & 97.2 & 19.44 & $5.39 \mathrm{E}-03$ & $3.57 \mathrm{E}-05$ & $5.36 \mathrm{E}-03$ \\
\hline 13075 & 22,920 & 20.8 & 4.16 & $9.08 \mathrm{E}-04$ & $8.33 \mathrm{E}-05$ & $8.24 \mathrm{E}-04$ \\
\hline 13076 & 15,405 & 18 & 3.6 & $1.17 \mathrm{E}-03$ & $3.57 \mathrm{E}-05$ & $1.13 \mathrm{E}-03$ \\
\hline 13077 & 17,985 & 30.4 & 6.08 & $1.69 \mathrm{E}-03$ & $3.57 \mathrm{E}-05$ & $1.65 \mathrm{E}-03$ \\
\hline 13078 & 22,905 & 19.1 & 3.82 & $8.34 \mathrm{E}-04$ & $8.33 \mathrm{E}-05$ & $7.51 \mathrm{E}-04$ \\
\hline
\end{tabular}

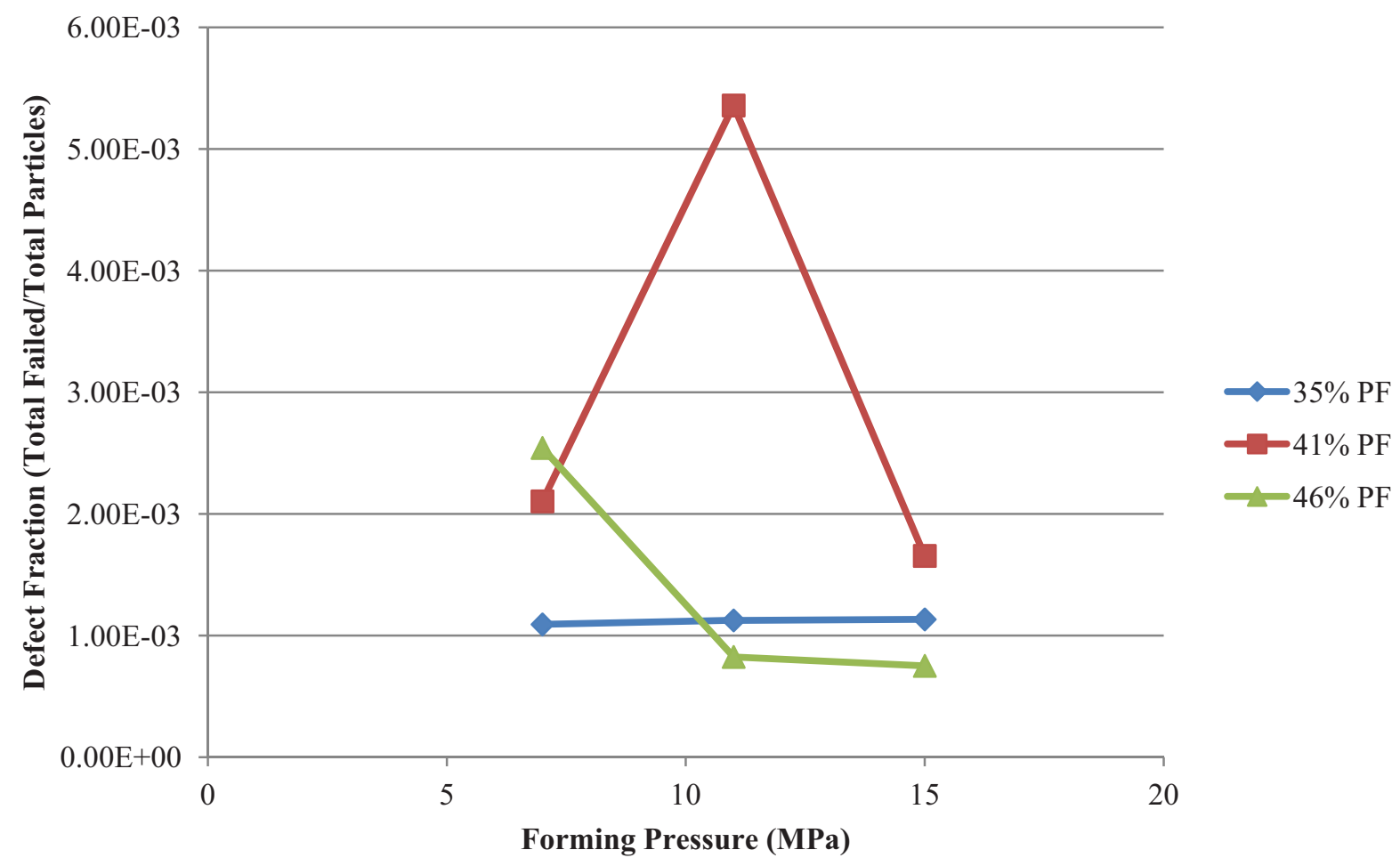

Figure 28. Graph of B\&W measured compact defect failure fraction as a function of forming pressure for 35 , 41 , and $46 \%$ packing fraction materials compacted at 7,11 , or $15 \mathrm{MPa}$. 


\subsection{Root Cause Analysis}

Discussions between INL and B\&W focused on three primary root causes for broken particles: (1) mechanical damage in the press; (2) damage induced by matrix composition; and (3) damage or errors resulting from the burn back chemical analysis method being used at $\mathrm{B} \& \mathrm{~W}$. To evaluate potential for mechanical and matrix damage, $\mathrm{B} \& \mathrm{~W}$ completed a series of compaction trials at lower temperatures using NUCO overcoated with both 5 and 7\% HEXA matrix compositions. The parameters for these trials, shown in Table 12, were based on parameters used at B\&W that produced green compacts with defect levels comparable to the base NUCO. The tests in Table 12 were intended to evaluate mechanical damage and matrix composition by pressing compacts using a range of temperatures below and above the curing point for the novolac resin used in the matrix at both 35 and 47\% PF. Samples pressed at 125 and $140^{\circ} \mathrm{C}$ had little if any curing in the die cavity; the curing of these compacts occurred during the carbonization thermal profile. Compacts pressed at $177^{\circ} \mathrm{C}$ are partially cured during the compaction process. Green compacts and heat treated compacts were submitted for deconsolidation as prior burn back testing yielded high defective particle levels. Damaged particles present in green compacts pressed at the lower temperatures $\left(125\right.$ and $\left.140^{\circ} \mathrm{C}\right)$ would indicate that the press is the root cause for damage. Damaged particles present in the high temperature $\left(177^{\circ} \mathrm{C}\right)$ green compacts or any of the heat treated compacts would indicate that the matrix is the root cause. Damage to compacts only at the $47 \%$ PF would indicate that the PF is too high. Additional tests discussed below were designed to evaluate the effectiveness of the chemical analysis method by a round robin testing of samples between ORNL and $\mathrm{B} \& \mathrm{~W}$.

Table 12. Test parameters for lower HEXA and temperature compaction trial at B\&W.

\begin{tabular}{|c|c|c|c|c|c|}
\hline Lot & $\begin{array}{c}\text { HEXA Content } \\
(\%)\end{array}$ & $\begin{array}{c}\text { Targeted Packing } \\
\text { Fraction }(\%)\end{array}$ & $\begin{array}{c}\text { Temperature } \\
\left({ }^{\circ} \mathrm{C}\right)\end{array}$ & $\begin{array}{c}\text { Compaction Pressure } \\
(\mathrm{MPa})\end{array}$ & $\begin{array}{c}\text { Hold Time } \\
(\mathrm{sec})\end{array}$ \\
\hline 13084 & 5 & 35 & 125 & 15 & 90 \\
\hline 13085 & 5 & 35 & 125 & 22 & 90 \\
\hline 13086 & 5 & 35 & 140 & 7 & 90 \\
\hline 13087 & 5 & 35 & 140 & 11 & 90 \\
\hline 13088 & 5 & 35 & 177 & 11 & 68 \\
\hline 13089 & 5 & 46 & 125 & 15 & 90 \\
\hline 13090 & 5 & 46 & 125 & 22 & 90 \\
\hline 13091 & 5 & 46 & 140 & 11 & 90 \\
\hline 13092 & 5 & 46 & 140 & 15 & 90 \\
\hline 13093 & 5 & 46 & 177 & 11 & 68 \\
\hline 13094 & 7 & 37 & 140 & 11 & 90 \\
\hline
\end{tabular}

Samples were compacted at temperatures of 125,140 , or $177^{\circ} \mathrm{C}$ with compaction pressures ranging from 7 to $22 \mathrm{MPa}$ to replicate parameters used in prior compaction experiments. The pressing rate, however, was decreased from $5 \mathrm{~mm} / \mathrm{second}$ to $2 \mathrm{~mm} / \mathrm{second}$ during compaction to closer match the rate used at ORNL for AGR-2 and AGR-3/4 compaction campaigns. HEXA loading was decreased from 7\% to $5 \%$ for all but one of the test conditions to evaluate the effect of matrix strength and rigidity during the curing process. All prior testing was conducted using 7\% HEXA loading in the matrix. Compacts pressed at $140^{\circ} \mathrm{C}$ had evidence of pullout of matrix on the punch faces (Figure 29). This is most likely due to the matrix being in a liquid state throughout compaction with little to no curing during the compaction cycle. Compacts were carbonized and heat treated during the week of January 2, 2012 and 
submitted for deconsolidation and leach analysis. [This was based on analysis of previous compacts where compacts pressed at lower temperatures of 55 and $125^{\circ} \mathrm{C}$ did not have any increased levels of defects when analyzed by deconsolidation. The sample pressed at $55^{\circ} \mathrm{C}$ also did not show any defects after deconsolidation and burn back while the sample pressed at $125^{\circ} \mathrm{C}$ had 1.1 defective particles after deconsolidation and burn back. Prior results using straight burn back results on these compacts measured 15.5 and 17 broken particles on the green compacts. Additional green and heat treated compacts pressed from the $7 \%$ matrix composition at 125 and $177^{\circ} \mathrm{C}$ were also submitted for deconsolidation as these compacts showed higher defect rates using the burn back method at B\&W.]

The final root cause being considered and evaluated is the chemical analysis method at $\mathrm{B} \& \mathrm{~W}$. The primary concern is that $\mathrm{B} \& \mathrm{~W}$ uses a $900^{\circ} \mathrm{C} / 15$-hour burn back to oxidize and remove the matrix and OPyC layers. This temperature may be too high, the thermal stress gradient to severe, or the hold time too long inducing damage in the TRISO particles. Selected heat treated NUCO compacts from lots 13072, 13074, and 13076 were shipped from B\&W to ORNL for deconsolidation and analysis. B\&W's defective particle results from these lots are shown in Table 11. ORNL deconsolidated five compacts from each lot of compacts and performed two 24 hour leaches. Results from lot 13072 showed 1.01 exposed kernels out of approximately 23,000 fuel particles. Results on the remaining two lots each resulted in $<0.1$ exposed fuel kernels out of approximately 15,500 and 18,000 fuel particles respectively. Overall analysis results were self consistent with second leaches and final water rinses coming in at roughly $10 \%$ of the preceding leach.

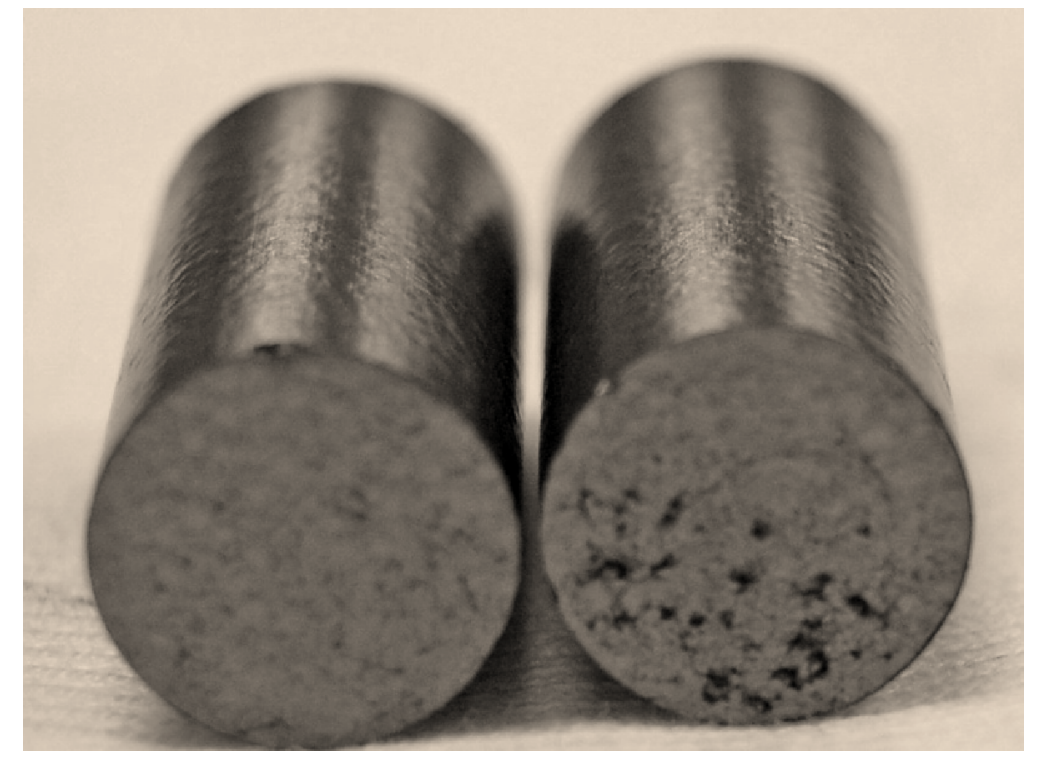

Figure 29. Photograph of compacts from lot 13091 pressed at $140^{\circ} \mathrm{C}$ and $11 \mathrm{MPa}$ forming pressure. Some compacts pressed at this condition showed pullout from adhesion of the matrix to the punch face.

The ORNL results strongly suggest that the burn back method employed at B\&W plays a significant role in the prior damage levels reported. ORNL is repeating the analysis on five additional compacts from the samples provided by B\&W for confirmation. ORNL has also provided well characterized LEUCO compacts from LEU06 to B\&W to serve as a reference standard for burn back and deconsolidation test methods. B\&W completed burn back and deconsolidation on two sets of five compacts each. The results from the first leach on deconsolidated compacts indicated 0.6 failed particles out of approximately 15,930 total fuel particles (defect rate of 3.1E-5). This measured particle failure rate compares well with test results from ORNL testing. ${ }^{6}$ Burn back analysis, however, indicated 38.2 failed particles (2E-3) on five fuel compacts. The large discrepancy between this value and historical data compiled at ORNL provides confirmation that the burn back method at $\mathrm{B} \& \mathrm{~W}$ is not providing reliable 
results for broken particle analysis. ORNL and B\&W collaboration on analytical methods was completed to identify differences and issues with the $\mathrm{B} \& \mathrm{~W}$ chemical analysis method and standardize the approaches to produce consistent results at either lab.

Mass loss and axial shrinkage results from the lower temperature compaction trials are shown in Table 13. In reviewing the shrinkage and mass loss data, one observation is worth noting: all compacts had measurable shrinkage from the as-pressed to heat treated conditions. Shrinkage for compacts pressed at 125 and $140^{\circ} \mathrm{C}$, which were cured in the carbonization furnace, is at least an order of magnitude higher than that observed for compacts pressed at $177^{\circ} \mathrm{C}$ and the higher pressing rate (see Figure 22). This likely resulted from the lower as-pressed matrix density, the slower forming rate, and the lower forming temperatures used during compaction. Mass loss was also more consistent and varied less as a function of forming pressure. Compacts formed at $140^{\circ} \mathrm{C}$ were noted to have a higher tendency to stick to the punch and die surface than did compacts pressed at 125 or $177^{\circ} \mathrm{C}$. This is likely due to the resin forming a liquid phase but not curing during compaction and could be eliminated with improvements to the lubricant used.

Table 13. Compact properties from lower HEXA and temperature compaction trial at B\&W.

\begin{tabular}{|c|c|c|c|c|c|c|}
\hline Lot & $\begin{array}{c}\text { Est. Particles } \\
\text { per Compact }\end{array}$ & $\begin{array}{c}\text { Est. Packing } \\
\text { Fraction } \\
(\%)\end{array}$ & $\begin{array}{c}\text { Est. Matrix } \\
\text { Density } \\
\left(\mathrm{g} / \mathrm{cm}^{3}\right)\end{array}$ & $\begin{array}{c}\text { Mass Loss } \\
(\%)\end{array}$ & $\begin{array}{c}\text { Radial } \\
\text { Shrinkage } \\
(\%)\end{array}$ & $\begin{array}{c}\text { Axial } \\
\text { Shrinkage } \\
(\%)\end{array}$ \\
\hline 13084 & 2956 & 34.0 & 1.68 & 5.51 & 1.73 & 3.59 \\
\hline 13085 & 2955 & 34.3 & 1.71 & 5.52 & 1.82 & 3.53 \\
\hline 13086 & 2954 & 33.0 & 1.61 & 5.60 & 1.89 & 3.06 \\
\hline 13087 & 2953 & 34.2 & 1.70 & 5.47 & 1.81 & 3.14 \\
\hline 13088 & 2955 & 34.9 & 1.75 & 5.24 & 1.08 & 0.11 \\
\hline 13089 & 4260 & 47.3 & 1.68 & 4.20 & 1.24 & 2.66 \\
\hline 13090 & 4267 & 47.6 & 1.71 & 4.09 & 1.22 & 2.64 \\
\hline 13091 & 4260 & 46.6 & 1.63 & 4.12 & 1.28 & 2.54 \\
\hline 13092 & 4260 & 47.5 & 1.69 & 4.21 & 1.23 & 2.52 \\
\hline 13093 & 4268 & 47.2 & 1.68 & 4.02 & 0.65 & 0.02 \\
\hline 13094 & 3156 & 35.8 & 1.67 & 4.98 & 1.63 & 3.27 \\
\hline
\end{tabular}

Overall defect fraction levels on green compacts are shown in Table 14. This value is an overall defect rate identified from deconsolidated compacts; defect fraction from the base NUCO has not been subtracted from this value. Analysis on the $35 \%$ packing fraction compacts showed 2.2 defective particles on compacts from lot 13084 . This corresponds to a defect rate of $1.49 \mathrm{E}-4$, which is a factor of 4.1 times higher than the base NUCO, but heat treated compacts from the same lot only had 0.9 defective particles in five compacts. It is likely that the sample size is not sufficiently high to be statistically significant. No defective particles were found from deconsolidation results on lots 13085 through 13088 from green or heat treated compacts. The results are also comparable to those obtained at ORNL on heat treated compacts, giving some indication that the deconsolidation test methods are comparable between ORNL and B\&W.

Heat treated deconsolidation results are also shown in Table 14. The results again show good success with the $35 \%$ packing fraction compacts as all but two conditions had defect rates lower than the base NUCO. The two conditions where the defect fraction exceeded the base NUCO were warm pressing conditions where compacts were pressed at $125^{\circ} \mathrm{C}$. In both sets of samples, the defective particle total 
was only 1 or 1.8 defective particles (Table 14) respectively. This may be a statistical anomaly due to the limited sample size. The $46 \%$ packing fraction heat treated compacts also show a similar trend as seen with green compacts in which defect rates increase with increased forming pressure. Lot 13091 showed an apparently significant increase in defect rates from green to heat treated compacts going from 0.0 to 11.2 defective particles. This might suggest that the carbonization/heat treatment is responsible for particle damage, but contradicts similar data obtained during the course of this work. Damage is likely occurring during compaction and point loading; larger sample sizes in both green and heat treated compacts would confirm this conclusion. Pressing compacts at the higher packing fraction will nonetheless require lower forming pressures to minimize any particle damage resulting from compaction.

An analysis of the $46 \%$ packing fraction compacts indicates higher levels of particle damage apparently associated with forming pressure. Higher defect levels were observed with higher forming pressures. Compacts pressed at $11 \mathrm{MPa}$ had defect levels below 2E-5 from the two cases tested, but the matrix density did not achieve the targeted value of $1.75 \mathrm{~g} / \mathrm{cm}^{3}$. Increasing the forming pressure beyond $11 \mathrm{MPa}$ improves matrix density, but also results in higher particle failure rates.

Table 14. B\&W deconsolidation data from low HEXA and temperature compaction trials.

\begin{tabular}{|c|c|c|c|c|c|}
\hline Lot & $\begin{array}{c}\text { NUCO Blend } \\
\text { Lot Failure } \\
\text { Rate }\end{array}$ & $\begin{array}{c}\text { Green Compact } \\
\text { Failed } \\
\text { Particles/5 } \\
\text { Compacts }\end{array}$ & $\begin{array}{c}\text { Green Compact } \\
\text { Failure Rate }\end{array}$ & $\begin{array}{c}\text { Heat Treated } \\
\text { Compact Failed } \\
\text { Particles/5 } \\
\text { Compacts }\end{array}$ & $\begin{array}{c}\text { Heat Treated } \\
\text { Compact Failure } \\
\text { Rate }\end{array}$ \\
\hline 13084 & $3.63 \mathrm{E}-05$ & 4.4 & $2.98 \mathrm{E}-04$ & 0.8 & $5.68 \mathrm{E}-05$ \\
\hline 13085 & $3.63 \mathrm{E}-05$ & 0 & $0.00 \mathrm{E}+00$ & 0.5 & $3.38 \mathrm{E}-05$ \\
\hline 13086 & $3.63 \mathrm{E}-05$ & 0 & $0.00 \mathrm{E}+00$ & 0.2 & $1.56 \mathrm{E}-05$ \\
\hline 13087 & $3.63 \mathrm{E}-05$ & 0 & $0.00 \mathrm{E}+00$ & 0.0 & $0.00 \mathrm{E}+00$ \\
\hline 13088 & $3.63 \mathrm{E}-05$ & 0 & $0.00 \mathrm{E}+00$ & 0.0 & $0.00 \mathrm{E}+00$ \\
\hline 13089 & $7.98 \mathrm{E}-05$ & 17.4 & $8.17 \mathrm{E}-04$ & 22.9 & $1.07 \mathrm{E}-03$ \\
\hline 13090 & $7.98 \mathrm{E}-05$ & 53.8 & $2.52 \mathrm{E}-03$ & 61.4 & $2.88 \mathrm{E}-03$ \\
\hline 13091 & $7.98 \mathrm{E}-05$ & 0 & $0.00 \mathrm{E}+00$ & 6.9 & $3.23 \mathrm{E}-04$ \\
\hline 13092 & $7.98 \mathrm{E}-05$ & 24.6 & $1.15 \mathrm{E}-03$ & 31.2 & $1.46 \mathrm{E}-03$ \\
\hline 13093 & $7.98 \mathrm{E}-05$ & 4.2 & $1.97 \mathrm{E}-04$ & 3.7 & $1.75 \mathrm{E}-04$ \\
\hline 13094 & $7.98 \mathrm{E}-05$ & 0 & $0.00 \mathrm{E}+00$ & 2.1 & $1.35 \mathrm{E}-04$ \\
\hline
\end{tabular}




\subsection{Root Cause Analysis Results Summary}

The following results may be summarized for the root cause analysis testing performed.

1. The B\&W burn-leach method for determining fuel particle damage is unusable.

2. Reduction in HEXA content and compact forming rate increases compact shrinkage during carbonization and the effect is more pronounced when curing is performed during the carbonization process.

3. There is no correlation between particle damage and potential sources of compacting press mechanical damage.

4. Particle damage is not increased by hot pressing with die curing and may be minimized by hot pressing, especially at high packing fractions.

5. Compacts made with both 5 and $7 \%$ HEXA passed particle damage tests. HEXA content and its association with matrix strength are not major factors in particle damage.

6. Compacting at packing fractions above $46 \%$ without particle damage will require lower pressures $(<11 \mathrm{MPa})$ resulting in lower matrix density fuel compacts.

7. Particle damage appears to be unrelated to compacting pressure below $46 \% \mathrm{PF}$. 


\section{SUMMARY}

- Warm pressing during the initial trials with surrogate TRISO fuel indicated that the novolac-based matrix compositions will not achieve the targeted density of $1.75 \mathrm{~g} / \mathrm{cm}^{3}$ of matrix density using these resins. The maximum matrix density achieved in trials with $\mathrm{ZrO}_{2}$ was approximately $1.50 \mathrm{~g} / \mathrm{cm}^{3}$. Warm pressing was eliminated as an option for NUCO containing compacts based on these results.

- Hot pressing of $\mathrm{ZrO}_{2}$ surrogate TRISO provided confirmation that higher temperatures would achieve matrix density near the targeted value of $1.75 \mathrm{~g} / \mathrm{cm}^{3}$ and packing fraction of greater than $46 \%$ by volume.

- Hot pressing of NUCO overcoated with a novolac-resin-based matrix can yield compacts that have a high matrix density and packing fraction. Matrix density values of 1.72 to $1.76 \mathrm{~g} / \mathrm{cm}^{3}$ were achieved over a range of hot-pressing conditions, yielding compacts with NUCO packing fractions of 46 to $48 \%$.

- Results from the factorial experiment indicate that all variables and interactions were significant at a $95 \%$ confidence level for matrix density with the exception of pressure. Hot pressing temperature was the dominant variable tested with higher temperatures yielding higher matrix density and higher packing fractions.

- Matrix composition was also identified as being a significant variable from the analysis. Hexion SD-1708 with SGL KRB-2000 yielded a higher matrix density than did Plenco 14838 resin with GrafTech GP-60, but both yielded compacts with matrix densities near the targeted level of $1.75 \mathrm{~g} / \mathrm{cm}^{3}$. The observed differences in matrix density are believed to be primarily because of the density of the synthetic graphite, not the resin source.

- Defects were observed in the end faces of initial compacts pressed at lower hot pressing temperatures. These defects were attributed to excess mold release pooling in the die and on the punch face. B\&W reduced the lubricant used and aligned the spray nozzles to more uniformly coat the die walls and punch faces. These steps eliminated the formation of the defects in subsequent compaction trials.

- Results of testing for time and temperature optimization indicate that the matrix density can be optimized by hot pressing at approximately $177^{\circ} \mathrm{C}$ with a 68 -second hold time at temperature, and that the process envelope is sufficiently large that time or temperature deviations from these conditions will still result in compacts with comparable matrix-density values.

- Results from the lower-pressure trials for the $46 \%$ packing fraction material indicate that the forming pressure can be lowered to as low as $14 \mathrm{MPa}$ without an adverse effect on matrix density, but $10 \mathrm{MPa}$ forming pressure yields matrix density at or below the targeted lower specification of $1.68 \mathrm{~g} / \mathrm{cm}^{3}$.

- Ceramography analysis of heat treated compacts shows regions of low and high flow as well as some fissures in the matrix. Data on heat-up rates for the fuel in the die cavity may allow compacting cycle adjustment to minimize flow variations and fissure formation.

- Heat treated fuel compacts with $46 \%$ PF showed evidence of particle-to-particle contact in the fuel compacts. None of these particles had any observable damage. Minimizing compaction pressure will be essential to reduce the likelihood for damaging the TRISO layers as a result of this increased contact at higher packing fractions.

- Ceramography analysis also shows particles near the surface. There is some evidence of surface texture that resulted from shrinkage of the matrix in the heat treatment cycle. No evidence of damage to the OPyC layer was observed in any of these particles.

- Shrinkage and weight loss data on heat treated compacts pressed at $177^{\circ} \mathrm{C}$ with a $5 \mathrm{~mm} / \mathrm{second}$ pressing rate and 7\% HEXA show a transition from compact shrinkage to growth with increasing packing fraction and with increasing compaction pressure. Mass loss is increased for all packing 
fractions at $7 \mathrm{MPa}$ compared to the 11 and $15 \mathrm{MPa}$ conditions with one explanation being that the higher green densities obtained with increased forming pressure may tend to seal the compact and restrict gaseous products from escaping during thermal treatment, resulting in compact expansion.

- Axial growth for these compacts is maximized for the condition of 35\% packing fraction compacted at $177^{\circ} \mathrm{C}$ and $15 \mathrm{MPa}$ forming pressure. This may be caused by a variety of factors. One possible reason is that the higher forming temperature and high matrix density seal the outer surface of the compact and restrict gases from escaping during carbonization and heat treatment cycles.

- Burn-leach testing on NUCO after the overcoating process provides indication that the overcoating process is not damaging fuel kernels. Results obtained on overcoated NUCO for the 35, 41, and $46 \%$ packing fraction materials showed damaged particle levels comparable to the base NUCO.

- Burn-leach testing on NUCO after discharge from the hopper into the die cavity shows the results are comparable to the base NUCO, which confirms that the automated die filling system is not damaging particles.

- Results from the packing fraction and pressure factorial experiment confirm that higher matrix density values can be achieved with lower packing fractions and lower compaction pressures. Matrix densities of $1.75 \mathrm{~g} / \mathrm{cm}^{3}$ can be achieved for a $35 \%$ packing fraction material at pressures of $\sim 9 \mathrm{MPa}$ while $47 \%$ packing fraction material requires $14 \mathrm{MPa}$ or greater to achieve the same matrix density.

- NUCO compacts have been fabricated at packing fractions ranging from 35 to $47 \%$, which meet or exceed specifications for broken particle levels. Compacts fabricated at B\&W and tested at ORNL had defect rates ranging from $6.50 \mathrm{E}-6$ to $4.40 \mathrm{E}-5$, both of which were lower than the defect fraction of the base NUCO lots used to fabricate these compacts. The estimated matrix density on these compacts ranged from 1.60 to $1.80 \mathrm{~g} / \mathrm{cm}^{3}$. Compacts with $46 \%$ packing fraction can be fabricated with low and acceptable particle defect failure rates when pressed up to $11 \mathrm{MPa}$; particle failure rates increase with higher forming pressure.

- Root cause analysis testing focused on three primary sources: mechanical damage at the press, damage from matrix properties, and chemical analysis method. Round robin testing of compacts at ORNL has indicated that the chemical analysis method used at B\&W was a significant source for the damaged particles reported to date. ORNL and B\&W are determining how the deconsolidation method being used at $\mathrm{B} \& \mathrm{~W}$ can be made comparable to the ORNL process.

- Reducing HEXA content and pressing rate resulted in compact shrinkage during carbonization and heat treatment cycles. Prior tests with 7\% HEXA and more rapid pressing rates resulted in expansion of the compacts during carbonization and heat treatment.

- Reducing the hot pressing temperature to $140^{\circ} \mathrm{C}$ resulted in matrix adhesion to the punch faces resulting in pullout on the compacts. This could be overcome with modifications to the mold release material but would require additional effort for optimization testing.

- Compact qualification testing should commence using forming conditions of $175 \pm 5^{\circ} \mathrm{C}$ for $70 \pm 5$ seconds and $12 \mathrm{MPa}$ forming pressure compacting NUCO overcoated at a targeted $41 \%$ packing fraction. ${ }^{7}$ Based on the results from the experimental trials, INL has confidence that these compacts will meet or exceed results from uranium contamination levels of $2 \mathrm{E}-5$.

- Compact qualification testing should commence using forming conditions of $175 \pm 5^{\circ} \mathrm{C}$ for $70 \pm 5$ seconds and $12 \mathrm{MPa}$ forming pressure compacting NUCO overcoated at a targeted $41 \%$ packing fraction. TFR-826, “AGR Compact Qualification Test Process Requirements,” Rev. 0, February 2012, Idaho National Laboratory. Based on the results from the experimental trials, INL has confidence that these compacts will meet or exceed results from uranium contamination levels of $2 \mathrm{E}-5$. 


\section{REFERENCES}

1 J. Phillips, E. Shaber, and S. Nagley, "Technology Selection for Cylindrical Compact Fabrication," Proceedings of HTR 2010, Paper 235, Prague, Czech Republic, October 18-20, 2010.

2 J. Phillips, S. Nagley, and E. Shaber, "Fabrication of uranium oxycarbide kernels and compacts for HTR fuel," NED-6612, Nuclear Engineering and Design, November 2011.

3 PLN-3755, 2011 “Compacting Scale-up Process - Detailed Test Results and Finalization Plan,” Rev. 0 .

4 PLN-2908, 2009, “AGR Fuel Development Compacting Scale-Up Plan,” Rev. 0.

5 PLN-3818, 2011, "Finalization Test Matrix and Plan - Compact Scale Up," Rev. 2.

6 J. Hunn, F. Montgomery, and P. Pappano, Data Compilation for AGR-2 UCO Variant Compact Lot LEU06-OP1-Z, Rev. 1, December 2009.

7 TFR-816, 2012, “AGR Compact Qualification Test Process Requirements,” Rev. 0. 